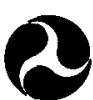

U.S. Department

of Transportation

National Highwrey

Trenfile Safely

Administrution

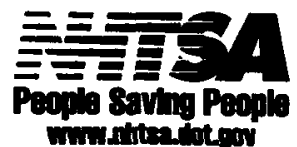

3

DOT HS 809192

October 2000

\title{
Field Test of On-Site Drug Detection Devices
}


This publication is distributed by the U.S. Department of Transportation, National Highway Traffic Safety Administration, in the interest of information exchange. The opinions, findings and conclusions expressed in this publication are those of the author(s) and not necessarily those of the Department of Transportation or the National Highway Traffic Safety Administration. The United States Government assumes no liability for its content or use thereof. If trade or manufacturer's names or products are mentioned, it is because they are considered essential to the object of the publication and should not be construed as an endorsement. The United States Government does not endorse products or manufacturers. 
Technical Report Documentation Page

\begin{tabular}{|c|c|}
\hline $\begin{array}{l}\text { 1. Report No. } \\
\text { DOT HS } 80.9 \quad 192 \\
\end{array}$ & 3. Recipieni's Catalog No. \\
\hline \multirow{3}{*}{$\begin{array}{l}\text { 4. Title and Subtitle } \\
\text { Field Test of On-Site Drug Detection Devices. }\end{array}$} & $\begin{array}{l}\text { 5. Report Date } \\
\text { October } 2000\end{array}$ \\
\hline & 6. Performing Organization Code \\
\hline & 8. Performing Organiżation Report No. \\
\hline $\begin{array}{l}\text { 7. Author(s) } \\
\text { Hersch, Rebekah K., Derinis J. Crouch, and Royer F. Cook }\end{array}$ & \\
\hline \multirow{3}{*}{ 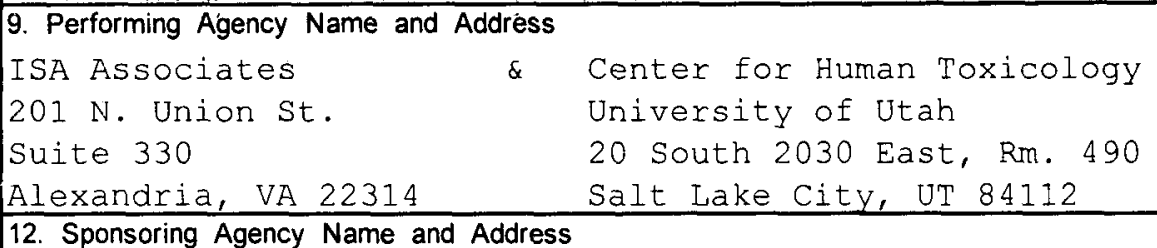 } & 10. Work Unit No. (TRAIS) \\
\hline & $\begin{array}{l}\text { 11. Contract or Grant No. } \\
\text { DTNH } 22-97-\mathrm{C}-05122\end{array}$ \\
\hline & 13. Type of Report and Period Covered \\
\hline \multirow[t]{2}{*}{$\begin{array}{l}\text { 12. Sponsoring Agency Name and Address } \\
\text { National Highway Traffic Safety Administration } \\
400 \text { Seventh St., SW } \\
\text { Washington, DC } 20590\end{array}$} & $\begin{array}{l}\text { Final Report } \\
\text { Sept. } 1997 \text { - October } 2000 \\
\text { 14. Sponsoring Agency Code }\end{array}$ \\
\hline & \\
\hline & \\
\hline
\end{tabular}

\section{Abstract}

This NHTSA-sponsored study reports the findings of a field evaluation of five on-site drug screening devices used by law enforcement to screen for illicit drugs among drivers suspected of driving under the influence (DUI) of alcohol or other drugs. In two major U.S. jurisdictions (Nassau County, New York and Houston, Texas), five of the leading on-site devices were field tested on 800 drivers apprehended for suspicion of DUI. Each urine specimen collected from an arrestee was tested with all five on-site devices; drug positive specimens and a sample of drug negatives were laboratory confirmed by Mass spectrometry. Police officers rated the devices on five dimensions. Field test results included: (1) the number of drug positives detected by each device across the five major drugs of abuse; (2) number of discrepancies among the five on-site devices and between the devices and the confirmations; and (3) mean officer ratings for each device. Implications for the uses of on-site devices by law enforcement for assessing illicit drug use by drivers is discussed.

\section{\begin{tabular}{l|l} 
17. Key Words & 18. Distribution Statement
\end{tabular}}

drugs and driving, law enforcement, On-site Document available to the public through drug testing, DUI enforcement, marijuana, the National Technical Information cocaine, opiates, amphetamines, PCP $\quad$ Service, Springfield, VA 22161

\begin{tabular}{|l|l|l|l|}
\hline $\begin{array}{l}\text { 19. Security Classif. (of this report) } \\
\text { unclassified }\end{array}$ & $\begin{array}{l}\text { 20. SECURITY CLASSIF. (of this page) } \\
\text { unclassified }\end{array}$ & 21. No. of Pages & Price \\
\hline
\end{tabular}




\section{Acknowledgments}

The authors would like to extend their sincere appreciation and thanks to the participating traffic division officers and staff of the Nassau County, NY Police Department and the Houston, TX Police Department. This research would not have been possible without them. We would also like to express our thanks to Biosite Diagnostics Corporation, American Bio Medica Corporation, Princeton BioMeditech Corporation and Roche Diagnostics Corporation for their complete cooperation, as well as for providing valuable information and training materials about their devices. 


\section{Table of Contents}

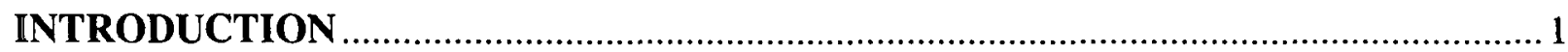

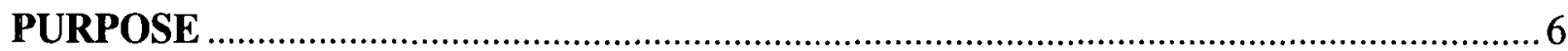

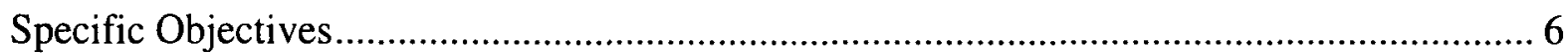

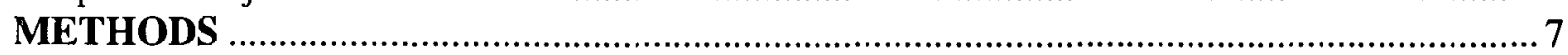

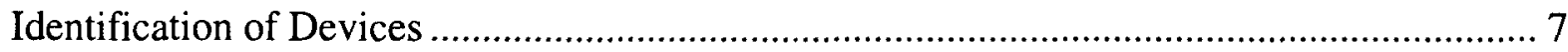

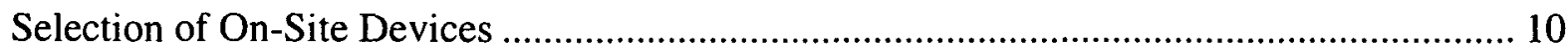

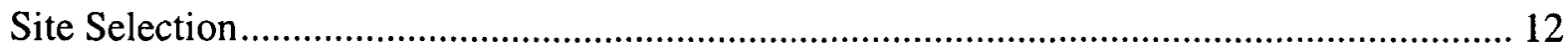

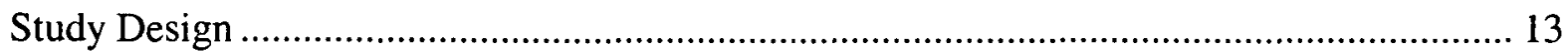

RESULTS

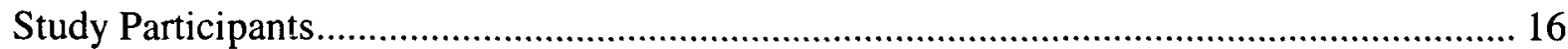

On-Site Device Results and MS Confirmations........................................................ 17

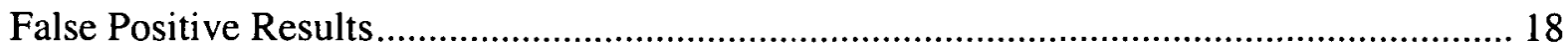

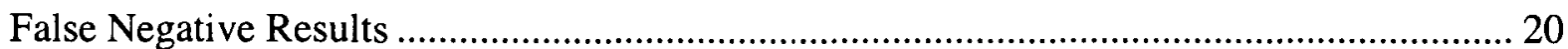

Unconfirmed Positive Results - Based On Analytical Cutoff ............................................. 22

Unconfirmed Positive Results - Based On Tested Drugs ................................................. 25

Comparison of Officer Test Results and Research Analyst Test Results ............................ 27

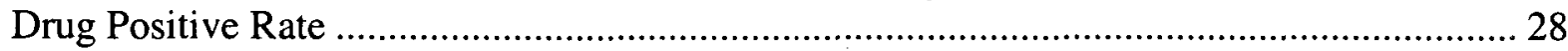

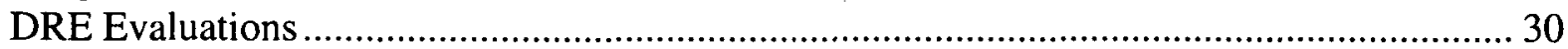

Officer Ratings and Interviews................................................................................. 32

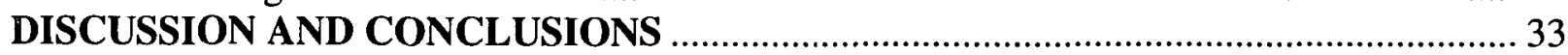

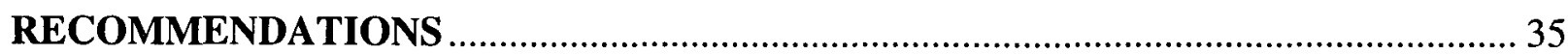

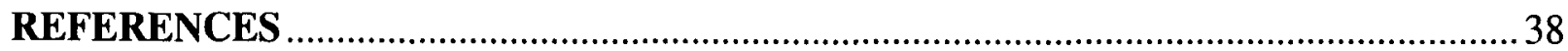

APPENDIX A: Research and Data Collection Guidelines ............................................41

APPENDIX B: Confirmation Testing Procedures ........................................................6 61 


\section{INTRODUCTION}

Numerous studies have reported the prevalence of drug use (including alcohol) by impaired drivers, injured drivers, and fatally injured auto drivers. A representative sample of these studies is shown in Table 1. Early studies of fatally injured driving populations, such as that reported by Garriott et al. (1977) provided an understanding of the prevalence of alcohol and other drugs in fatally injured drivers in the U.S. However, substance use in transportation safety is not a problem unique to the US, as demonstrated by Robinson (1979) in Ireland and Cimbura et al. (1982) in Canada. The early studies by Garriott and Robinson provide a historical prospective, but their findings have limited applicability today because comprehensive testing was not performed, drug use patterns have changed and the analytical methods available to these authors lacked the sensitivity to screen and reliably quantify cannabinoids in biological fluids.

The study by Reeves et al. (1979) provided some of the first insight into the extent of marijuana use by motor vehicle operators. Reeves et al., showed that $16 \%$ of a selected sample of arrested drivers had cannabinoids in their urine. These data were consistent with those reported by Cimbura who also tested for cannabinoids in blood and urine. The fatally injured driver study by Terhune et al. (1992) further documented the extent of marijuana use and also indicated that cocaine use by drivers might be of growing concern.

Willette and Walsh (1998) pointed out that the full impact of drugs on traffic safety was unknown in the early 1980 s and unfortunately this remains true today. However, there are some data that have emerged over the last decade that provide insight regarding the overall extent of the problem. Williams et al. (1985) reported a "high risk" sample of 440 young male auto drivers killed in California traffic crashes. This study showed that $70 \%$ of blood specimens collected from these drivers contained alcohol, $37 \%$ contained cannabinoids, and $11 \%$ contained cocaine. A report by Mason and McBay (1984, not shown in Table 1) also addressed the question of cannabinoid use by drivers. This study of 600 driver fatalities in North Carolina demonstrated that over $79 \%$ had detectable blood alcohol concentrations and $7.8 \%$ showed evidence of cannabinoids. 
Table 1

\begin{tabular}{|c|c|c|c|c|c|c|c|c|c|c|}
\hline REFERENCE & $\begin{array}{l}\text { GARRIOTT } \\
1977 \\
\text { Fatals } \\
\text { Auto }\end{array}$ & $\begin{array}{c}\text { ROBINSON } \\
1979 \\
\text { Impaired } \\
\text { Auto }\end{array}$ & $\begin{array}{c}\text { CIMBURA } \\
1982 \\
\text { Fatals } \\
\text { Auto }\end{array}$ & $\begin{array}{c}\text { TERHUNE* }^{*} \\
1982 \\
\text { Injured } \\
\text { Auto }\end{array}$ & $\begin{array}{l}\text { REEVES } \\
1979 \\
\text { Impaired } \\
\text { Auto }\end{array}$ & $\begin{array}{c}\text { WILLIAMS* } \\
1985 \\
\text { Fatals } \\
\text { Auio }\end{array}$ & $\begin{array}{c}\text { LUND } \\
1988 \\
\text { Volunteers } \\
\text { Truck }\end{array}$ & $\begin{array}{c}\text { CAMPBELL } \\
1989 \\
\text { Volunteers } \\
\text { Truck }\end{array}$ & $\begin{array}{c}\text { TERHUNE } \\
1992 \\
\text { Fatals } \\
\text { Auto }\end{array}$ & $\begin{array}{c}\text { CROUCH }^{*} \\
1993 \\
\text { Fatals } \\
\text { Truck }\end{array}$ \\
\hline TOTAL CASES & 127 & 425 & 401 & 506 & 1792 & 440 & 300 & 500 & 1882 & 168 \\
\hline DRUGS & & & & & & & & & $18 \%$ & \\
\hline ETHANOL & $61 \%$ & $83 \%$ & $57 \%$ & $25 \%$ & & $70 \%$ & $1 \%$ & NA & $52 \%$ & $13 \%$ \\
\hline DRUGS & $18 \%$ & $27 \%$ & $26 \%$ & $22 \%$ & & $>40 \%$ & & $9 \%$ & $18 \%$ & \\
\hline $\begin{array}{l}\text { DRUGS OR } \\
\text { ETHANOL }\end{array}$ & $70 \%$ & $86 \%$ & $69 \%$ & $38 \%$ & & $81 \%$ & $29 \%$ & $10 \%$ & & $33 \%$ \\
\hline THC & NA & NA & $\begin{array}{c}9 \% \text { URINE } \\
3 \% \text { BLOOD }\end{array}$ & $\mathbf{9 \%}$ & $16 \%$ & $37 \%$ & $16 \%$ & $5 \%$ & $7 \%$ & $13 \%$ \\
\hline COCAINE/BZE & $<1 \%$ & NA & $<1 \%$ & $2 \%$ & & $11 \%$ & $2 \%$ & $1 \%$ & $5 \%$ & $8 \%$ \\
\hline DIAZEPAM/NOR & $10 \%$ & $19 \%$ & $3 \%$ & $7 \%$ & & $4 \%$ & $4 \%$ & & $2 \%$ & \\
\hline OTHER BENZOS & NA & $2 \%$ & $<1 \%$ & $2 \%$ & & & & & $1 \%$ & \\
\hline AMPHETAMINE & & NA & & & & $<1 \%$ & $\begin{array}{c}\text { AMP+METH } \\
2 \%\end{array}$ & $<1 \%$ & $<1 \%$ & $4 \%$ \\
\hline METHAMPHETAMINE & & NA & & AMPHET & AMINE & $3 \%$ & & $<1 \%$ & $2 \%$ & $7 \%$ \\
\hline PHENTERMINE & & NA & & \& RELAT & ED 1\% & & & $<1 \%$ & & $<1 \%$ \\
\hline PPA & & NA & & & & $3 \%$ & COMBINED & & & $<1 \%$ \\
\hline EPHEDRINE & & NA & & & & $2 \%$ & $12 \%$ & $2.2 \% \%^{\star \star}$ & & $7 \%^{\star \star}$ \\
\hline PCP & & NA & & & & $4 \%$ & & & & \\
\hline BARBITURATES & $3 \%$ & $4 \%$ & $<1 \%$ & $3 \%$ & & $2 \%$ & $1 \%$ & & $2 \%$ & \\
\hline CODEINE & $<1 \%$ & $<1 \%$ & $2 \%$ & $<1 \%$ & & & & & $<1 \%$ & \\
\hline ANTIHISTAMINES & $2 \%$ & $<1 \%$ & $2 \%$ & NA & & & & & $<1 \%$ & \\
\hline METHAQUALONE & $2 \%$ & $<1 \%$ & $<1 \%$ & $<1 \%$ & & & & & & \\
\hline PROPOXYPHENE & $2 \%$ & NA & $<1 \%$ & $<1 \%$ & & & & & & \\
\hline OPIATES & & & & & & $2 \%$ & & & $<1 \%$ & \\
\hline 2 OR MORE DRGS & $5 \%$ & $1 \%$ & $5 \%$ & $11 \%$ & & $43 \%$ & & & & $14 \%$ \\
\hline
\end{tabular}


Soderstrum et al. (1988) found that, of 1,023 patients admitted to The Maryland (Baltimore) Shock and Trauma Unit, $34.7 \%$ had very recently used marijuana (i.e., greater than $3 \mathrm{ng} / \mathrm{mL}$ tetrahydrocannabinol in serum) and $33 \%$ had BACs greater that $100 \mathrm{mg} / \mathrm{dL}(0.10 \%)$. Lindenbaum et al., (1989) at the Albert Einstein Trauma Center (Philadelphia) found 54\% of admissions tested positive for cocaine, $37 \%$ for cannabis, $35 \%$ for alcohol, $10 \%$ for barbiturates, and $7 \%$ for benzodiazepines.

The recent comprehensive study by Terhune showed that these drugs remain among the most commonly detected by fatally injured drivers (Terhune et al., 1992). In this study, samples were collected from 1,882 fatally injured drivers from seven states with each sample tested for more than 40 drugs.

Table 1 also shows data from three studies of drug use by truck drivers. The Lund et al., (1988) study of 300 paid volunteer drivers randomly selected at an interstate weigh station demonstrated that $29 \%$ were positive for drugs and less than $1 \%$ were positive for ethanol. The table also shows a British Columbia study (Campbell, 1989) where truck drivers were also randomly selected at weigh stations. In this study, $2 \%$ of the drivers admitted to recent alcohol use and $9.6 \%$ tested positive for drugs. Crouch and his associates tested fatally injured drivers of large trucks and found that $1 / 3$ contained psychoactive drugs or alcohol (Crouch et al., 1993). In this study, alcohol and cannabinoids were detected in $13 \%$ of the drivers, cocaine in $8 \%$, and sympathomimetic amines (e.g., amphetamines, methamphetamines, and similar over the counter preparations) in $11.3 \%$ of the drivers.

Although alcohol, cannabinoids, and cocaine remain the most prevalent drugs detected in drugs-and-driving studies, Table 1 shows that other drugs were also detected and, therefore, should not be discounted. Amphetamine, methamphetamine and related sympathomimetic amines were frequently detected in the more recent studies (Williams, 1985; Lund, 1988; Terhune, 1992; Crouch, 1993). Some drugs, such as barbiturates (southern California), and PCP show regional or local areas of prevalence. Benzodiazepines (e.g., valium, xanax, etc.) have not been frequently detected in recent studies; however, they are among the most prescribed class of drugs in the US, can impair driving ability, and were detected in approximately $5 \%$ of the drivers in the Terhune fatal injury study. The same study indicated that $2 \%$ of the drivers were taking barbiturates. 
Comparatively little data have been published on the prevalence of drugs in drivers detained by the police for erratic driving. Compton and Anderson summarized the studies in this area in a NHTSA staff report (Compton \& Anderson, 1985). These authors reported that the prevalence of drugs in arrested drivers with BAC concentrations below $0.10 \%$ was between $14 \%$ and $50 \%$. The most frequently encountered drugs in order of prevalence were marijuana, tranquilizers and sedatives, hallucinogens (PCP), cocaine, amphetamines, and opiates. In the Virginia data reported by Compton and Anderson, blood from 788 drivers was tested and $16 \%$ of the samples contained one or more drugs. A six-year California study showed annual prevalence rates of $30 \%$ to $50 \%$ for drugs in arrested drivers. A second California study showed that between $14.4 \%$ and $23 \%$ of the blood samples collected from impaired drivers contained marijuana.

As advancements in drug testing technology have developed, these new technologies have been applied to testing samples collected from impaired, injured, and fatally injured drivers. Recently, an expedient urinalysis drug screening technology was introduced. These commercially available "on-site drug screening devices" are immunoassay based, require no sophisticated instrumentation, and do not require a permanent laboratory or extensively trained personnel. Several devices are currently described in the literature and are discussed below. These devices have been advocated for use in clinical settings, the criminal justice system, nuclear power generating plants, offshore oil drill platforms, commercial trucking, and highway safety. Several studies have been performed to assess the sensitivity and selectivity of on-site testing devices (Fitzgerald, 1994; Wu, 1994; Koch, 1994; Baker, 1991; Armbruester, 1992; Ferrara, 1994; Jenkins, 1995; Towt, 1995). Unfortunately, these studies have been performed primarily in laboratories using trained laboratory professionals and have compared a single onsite drug test device to laboratory based immunoassay tests such as Enzyme Mediated Immunoassay Technique (EIA), Radioimmuncassay (RIA), and Flouresences Polarization Immunoassay (FPIA) and/or with Gas Chromatography/Mass Spectrometry (GC/MS) results.

The devices have several potential uses in support of NHTSA's efforts to improve highway safety. For example, on-site test device results could be used to corroborate the field sobriety assessments of drivers detained and evaluated by Drug Recognition Technicians who are trained using NHTSA-approved Drug Evaluation and Classification (DEC) training procedures. Results could augment the DEC evidence presented in legal proceedings of drivers charged with 
driving under the influence. Further, on-site tests could be used at the roadside to assist officers in deciding whether to arrest suspected drug-impaired auto or truck drivers. To evaluate the devices' potential for use in traffic safety, NHTSA designed and funded a study to have three analytical laboratories evaluate three on-site urine drug-testing devices. Specifically, the study was designed to be the first multi-site evaluation comparing on-site test results to urinalysis drug test results using EIA immunoassay testing and with GC/MS confirmation. Each laboratory operated independently in sample selection, analysis, data interpretation, and reporting. That study showed consistent results between the laboratories (Crouch, 1997).

Brookoff et al. (1994) used on-site testing devices in a study that found a $58 \%$ prevalence rate for drugs in subjects arrested for reckless driving (who were not found to be impaired by alcohol). The Brookoff team found that $33 \%$ of their sample tested positive for marijuana, $13 \%$ for cocaine, or $12 \%$ for both. (Because of sampling flaws in the study, these drug test rates should not be interpreted as drug prevalence rates for reckless drivers.) Interestingly, the on-site device (Microline) used by Brookoff and his colleagues generated a significant false positive rate for marijuana when compared to GC/MS results.

In a recent study by Walsh, Buchan, and their associates that is very similar to the study reported here, four on-site drug screening devices were evaluated in a law enforcement setting (Walsh et al., 1997; Buchan et al., 1997). As in the study reported here, the results of the on-site devices were compared to laboratory GC/MS tests $(n=305)$. Prevalence rates for cannabinoids, cocaine/metabolites, and opiates were $15.5 \%, 13.2 \%$ and $0.7 \%$, respectively. The four on-site devices used in that study - Triage ${ }^{\circledR}$, Abu-Sign $®$, OnTrak $®$, and TesTcup $®$ - were rated on ease of handling, time to conduct the test, specimen handling, reagent mixing, and readability of results by the three university-based evaluators. The four on-site devices were also assessed on their sensitivity and specificity (compared to GC/MS) and their cost. Abu-Sign® ${ }^{\circledR}$ and OnTrak® were clearly superior to the other two tests, although the cost of OnTrak® was a fraction of the cost of the other three. All four tests displayed high ( $96 \%$ or higher) levels of specificity (Buchan et al., 1997). Walsh and his associates concluded that routine use of these devices was feasible and that the devices could be integrated into police operations. However, it should be noted that in their study, although law-enforcement personnel collected the urine specimens, laboratory personnel conducted the on-site test - not officers. Therefore, although the Walsh study provides valuable 
information on the accuracy of on-site drug screening devices, it did not assess how well policeadministered on-site tests performed.

\section{PURPOSE}

This report describes results from a study funded by NHTSA to assess the utility of on-site testing devices when used by police officers. It is the first comprehensive study to systematically select the on-site devices to be used, capture a representative sample of DUI arrestees in two major urban areas, evaluate the accuracy of five on-site testing devices when used by actual arresting officers, and provide police officer subjective ratings of the on-site devices.

The study had multiple objectives. First, we needed to ensure that a sample of commercially available on-site drug screening devices -- for the purposes of police determinations of drug use by drivers -- were being assessed. The accuracy of the devices then had to be assessed against the most reliable standard available -- GC/MS tests. However, perhaps the key distinguishing element of this study was that it was a field test. This project was designed to assess how well the devices perform when they were taken out of the laboratory and placed in the hands of law enforcement personnel. This element was important because previous evaluations of these devices were performed in laboratories using trained laboratory personnel.

\section{Specific Objectives}

The study had four primary objectives:

1) To select on-site drug screening devices for use by police for the enforcement of drugs and driving laws that best met objective and scientifically based criteria.

2) To evaluate the accuracy of the selected on-site drug screening devices when used in a law enforcement field setting to test persons suspected of driving under the influence of a substance.

3) To evaluate the feasibility of using on-site drug screening devices in a law enforcement field setting as supporting evidence of drug use by impaired drivers.

4) To compare the results of on-site drug screening devices with the results of the DRE procedures. 


\section{METHODS}

In September 1997, ISA Associates, Inc. (ISA) and the University of Utah's Center for Human Toxicology (CHT) received a contract to conduct a field test of five on-site drug testing devices. The major tasks of the study were: 1) identify the pool of available on-site devices; 2) select five on-site drug testing devices for testing; 3) identify two study sites, each of which could provide a sample size of 400 arrested drivers; 4) train police officers and field technicians in specimen collection and device testing; 5) obtain subjective assessments of the on-site devices from the law enforcement officials and on-site research analyst; 6) conduct confirmation testing using GC/MS on all positive samples and $5 \%$ of the negative samples; and 7) submit reports to NHTSA throughout the project.

\section{Identification of Devices}

Two of the senior study personnel, Mr. Crouch and a project consultant, Dr. Michael Walsh, had performed research recently using on-site testing devices (Buchan, 1997; Crouch, 1997; 1998). This experience provided substantial knowledge of the scientific literature about the use and effectiveness of on-site devices as well as the manufacturer's literature on the devices. We supplemented this knowledge and our collective reprint files by performing a computer search of the scientific literature for references to on-site testing devices. These searches were performed both at $\mathrm{CHT}$, through a computer interface with the library facilities at the University of Utah, and at ISA, where an extensive search was made on the Internet. The search was limited to the last ten years when these devices become commercially available and began to be evaluated scientifically. These computer searches were supplemented with abstracts from recent meetings of the American Academy of Forensic Sciences, the American Association of Clinical Chemistry, the Society of Forensic Toxicologists, and similar scientific meetings. We also performed extensive searches to identify on-site device manufacturers. Once manufacturers were identified, they were contacted and asked to provide information about their products and referrals to additional manufacturers.

Data about each of the devices was compiled from three major sources. We contacted the FDA to obtain a list of approved devices and contacted manufacturers to provide product information. The information requested included availability of devices, cost, volume 
reduction(s) in cost, testing procedures, drugs/metabolites tested, antibody target analytes, storage requirements, and any additional test materials that are needed. Manufacturers were also asked if their devices tested for the presence of a single drug or for multiple drugs simultaneously. The scientific literature and the experience of ISA staff, Mr. Crouch, and Dr. Walsh were used to assess the accuracy and reliability of the devices based on the following criteria: 1) manufacturer criteria; 2) procedural criteria; 3) practical considerations and experience with the product; 4) scientific credibility of the device; and 5) cost. These criteria are described below.

Manufacturer Criteria. The manufacturer had to be a stable business entity, responsive, and able to provide the product expeditiously. Communications with the manufacturers were used to assess their willingness to cooperate and provide product information, their technical expertise, and their willingness to support users in the field.

Procedural Criteria. The manufacturer's recommended procedures were reviewed for simplicity, analysis time, number of reagents, number of steps, stability of the test results, and applicability for use by non-technical analysts. Whenever possible, sample devices were obtained from the manufacturers and the tests were performed at CHT. Experience has shown that one difficulty encountered with on-site devices is determining whether a test result is positive or negative. The ambiguity of the test results was a major criterion. The selection criteria needed to accommodate the field evaluation requirement of this project. Here the experience of Dr. Walsh was invaluable since he had already performed a field assessment of four devices (Buchan, 1997). Assessments of the accuracy and reliability of the devices were based on previous laboratory assessments.

Practical Considerations. Practical considerations included storage requirements, shelf life, special requirements for disposal, and the need for additional materials. The investigators relied primarily on their collective experience with the devices (Buchan, 1997; Crouch, 1997; 1998) to comment on the practical considerations of the devices.

Scientific Credibility. Information gathered from the scientific literature review, manufacturers, and product use references, was used to assess the accuracy and reliability of the devices. 
Numerical ratings of specific elements within each of these criteria were conducted. These elements and ratings included:

$\begin{array}{ll}\text { Test Panel } & 0=\text { Single, } 1=\text { Multiple } \\ \text { Drugs Tested } & 0=<\text { NIDA-5, } 1=\text { NIDA-5 } \\ \text { Urine Handling } & 0=\text { Aliquoting, } 1=\text { None } \\ \text { Number of Reagents } & 0=2,1=1,2=0 \\ \text { Mixing } & 0=\text { Required, } 1=\text { Not Required } \\ \text { Reaction Timed } & 0=\text { Yes, } 1=\text { Not Required } \\ \text { Reading Timed } & 0=\text { Yes, } 1=\text { Not Required } \\ \text { Analysis Complexity } & 1-4 \text { (Complex - Very Simple) } \\ \text { Storage } & 0=\text { Refridgeration, } 1=\text { Room Temperature } \\ \text { Literature } & 0=\text { None, } 1=\text { Some } \\ \text { Literature Supports } & \\ \quad \text { Product } & 0-4 \text { (None-Substantial) } \\ \text { Manufacturer Experience } & 0-4 \text { (Little Experience }- \text { Very Experienced) } \\ \text { Rater Confidence } & 0-6 \\ \text { FDA Clearance } & 0=\text { None, } 1=\text { Some Drugs/Pending, } 4=\text { Approved }\end{array}$

The ratings provided a numerical score that was used to group the devices for possible selection. Devices were recommended that, at a minimum, tested for the drugs indicated in the RFP (referred to above as NIDA-5). These drugs included amphetamines (amphetamine and methamphetamine), cocaine/metabolites (BZE), opiates, marijuana metabolite (THC-COOH), and phencyclidine (PCP). With the exception of PCP, these drugs were among the most common drugs detected in previous drugs and driving studies (Table 1). Additional drug classes were omitted based on a joint decision between NHTSA, ISA, and CHT. Originally, approximately 30 devices were identified. Sixteen of those devices had sufficient information to allow the research team to evaluate and rate the device. The research team was unable to obtain sufficient information the manufacturers to evaluate the remaining devices. The sixteen devices that were evaluated and rated by the research team are listed in Table 2. 


\section{Table 2 \\ Identified On-Site Devices}

Product

AccuSign $®$

accuPinch ${ }^{\circledR}$

EZ-Screen ${ }^{\circledR}$

EZ-Screen® Profile

Fingerprint-DOA®

First Check ${ }^{\circledR}$

FRONTLINE®

OnTrak®

Pharmscreen ${ }^{\circledR}$

Rapid Drug Screen ${ }^{\circledR}$

Status DS®

TesTcup ${ }^{\circledR}$

TesTstikß

Triage ${ }^{\circledR}$

Verdict ${ }^{\circledR}$

Visualine IIß

\section{Source}

Princeton Biomedical Corporation, Princeton, NJ

Hycor Biomedical, Inc., Irvine, CA

Editek, Inc., Burlington, NC

Editek, Inc., Burlington, NC

Biotek, Inc., Fairfax, VA

Worldwide Medical Corp., Irvine, CA

Boehringer Mannheim, Indianapolis, IN

Roche Diagnostic Systems, Inc., Somerville, NJ

PharmChem Laboratories, Inc., Menlo Park, CA

American Bio Medica Corp., Ancramdale, NY

Orion Diagnostica, Inc., Somerset, NJ

Roche Diagnostic Systems, Inc., Somerville, NJ

Roche Diagnostic Systems, Inc., Somerville, NJ

Biosite Diagnostics, San Diego, CA

Editek, Inc., Burlington, NC

Sun Biomedical Laboratories, Inc., Cherry Hills, NJ

\section{Selection of On-Site Devices}

ISA and CHT recommended and NHTSA selected the following on-site devices for the evaluation:

AccuSign ${ }^{\circledR}$, Princeton Biomedical Corporation, Princeton, NJ

OnTrak TesTcup-5®, Roche Diagnostic Systems, Inc, Somerville, NJ

OnTrak TesTstik®, Roche Diagnostic Systems, Inc, Somerville, NJ

Rapid Drug Screen®, American Bio Medica Corp, Ancramdale, NY

Triage ${ }^{\circledR}$, Biosite Diagnostics, San Diego, CA

The cutoff values reported by the manufacturers for the on-site devices were consistent with the 1992/1993 federal recommendations and are shown below (DOT, 1992; DHHS, 1993).

$\mathrm{THC}-\mathrm{COOH}$

Cocaine (BZE)

Amphetamines

Opiates

Phencyclidine (PCP)
$50 \mathrm{ng} / \mathrm{mL}$

$300 \mathrm{ng} / \mathrm{mL}$

$1,000 \mathrm{ng} / \mathrm{mL}$

$300 \mathrm{ng} / \mathrm{mL}$

$25 \mathrm{ng} / \mathrm{mL}$

The method of analysis for each of the devices is detailed in Appendix A: Research and Data Collection Guidelines. The following is a summary of the method used by each device. 
The AccuSign $\otimes$ drug tests were performed by placing three drops of urine from the specimen into the sample well and allowing the reaction to proceed. After approximately two-tofive minutes, color appeared at the "Control Line" indicating that the analysis results could be read. Results were read within ten minutes.

The OnTrak TesTcup-5® is an integrated urine collection and drug-testing device. No urine or reagent handling was required after the urine was collected. To initiate an analysis, the lid of the cup was turned to the "TEST" position and the cup was tilted forward for approximately ten seconds then returned to its upright position. After about five-to-ten minutes, blue bands were visible in the "Test Valid" window and the drug test results could be read.

Each OnTrak TesTstik $B^{\circledR}$ is designed to detect only one class of illicit drug. This is in contrast to the other devices that tested for a battery of five drugs/metabolites simultaneously. To perform the TesTstik ${ }^{\circledR}$ analysis, the protective sample pad cover was retracted. The exposed sample pad of the TesTstik ${ }^{\circledR}$ was immersed in the urine for approximately ten seconds. The test was allowed to proceed until a distinct blue band formed in the "TEST VALID" window. The drug test result then was read. Five drug class specific TesTstiks® were needed for a complete drug screen.

To perform an analysis using Rapid Drug Screen ${ }^{\circledR}$, the testing cup was first filled with urine. Then the Rapid Drug Screen $®$ card was inserted through the safety seal tape covering a slit in the cap of the testing cup. The Rapid Drug Screen® was allowed to contact the urine and the urine to migrate up the testing card. Negative results were read after approximately three minutes and positive results were evident in eight-to-ten minutes.

To initiate a Triage ${ }^{\circledR}$ test for drugs of abuse, the operator used a pipette provided by the manufacturer to transfer a portion of urine sample $(40 \mu 1)$ to a reaction cup on the device. The reaction mixture then was allowed to incubate for ten minutes at room temperature. Again using a pipette, the reaction mixture was transferred from the reaction cup to the detection area of the device. The mixture was allowed to soak completely though the absorbent detection area. Three drops of the wash solution then were added to the detection area and this was allowed to soak through the absorbent area. Results were read anytime within five minutes. This was the only device in which a color development indicated a positive test. 


\section{Site Selection}

The study required the participation of two police departments with sufficient DUI arrests to obtain four hundred urine samples each during the data collection period (approximately eight months). In addition, the sites needed to have strong Drug Recognition Evaluation (DRE) programs. NHTSA staff identified ten states that had sufficiently mature DRE programs to meet the needs of the field test. These states were New York, Maryland, Minnesota, Wisconsin, Texas, Colorado, Arizona, California, Hawaii, and Oregon. With assistance from State DRE Coordinators and NHTSA Regional Offices, the following sites were identified:

$\begin{array}{ll}\text { Colorado: } & \text { Denver } \\ \text { New York: } & \text { Nassau County } \\ \text { Arizona: } & \text { Phoenix } \\ & \text { Mesa } \\ \text { Texas: } & \text { Houston } \\ & \text { San Antonio } \\ \text { Wisconsin: } & \text { Milwaukee } \\ & \text { Madison } \\ \text { Oregon: } & \text { Multnomah County }\end{array}$

ISA staff contacted each site and obtained detailed information about the following selection criteria: 1) characteristics of the law enforcement agency and jurisdiction (number of officers, number of DRE officers, number of traffic division officers, square mileage and population size of police district, etc.); 2) DRE program and procedures; 3) local DUI procedures; 4) availability of a central testing facility for DUI processing; 5) willingness of the department to allow officers or research staff to obtain a urine sample from DUI suspects; 6) legal barriers to obtaining consent to obtain a urine sample in DUI arrests; 7) types of drugs in the driving populations; and 8) willingness of the department to participate as a study site.

A number of the sites were eliminated early in the site selection process either because there was no central testing facility within the law enforcement jurisdiction or because the implied consent laws in DUI cases made it difficult to obtain urine samples. After careful consideration of all the selection criteria, Nassau County, NY and Houston, TX were selected as the field test sites. 


\section{Study Design}

The study design, including training and site preparations, sample size, specimen handling procedures, data collection procedures, and confirmation procedures are described below.

Training and site preparations. ISA staff met with representatives from the Houston and Nassau County Police Departments as well as representatives from the local District Attorney's Office to discuss the study and data collection procedures. Informed consent documents were reviewed and approved by both police departments. The informed consent documents clearly indicated that the samples were to be collected anonymously and that the results of the tests could not be used against the participants in any legal proceeding.

In both Nassau County and Houston, an on-site research analyst was hired to lead the data collection. Dr. Hersch and Mr. Crouch supervised the data collection. The research analysts and the police central testing/traffic division personnel participated in a three-hour training session conducted by Mr. Crouch and Dr. Hersch. During the training session, videotapes, prepared by each of the manufacturers, were presented. Mr. Crouch then demonstrated how to perform each test with urine samples known to be drug-free and known to be cocaine positive. Finally, participants received hands-on experience with each of the devices. The manufacturers were invited by the research staff to visit each site and provide on-site training for the officers and research analysts. The research analysts received additional training on field-test procedures; specimen handling, labeling, and shipping; and record keeping.

Sample size. In each site, 400 urine samples were collected and tested. Sample sizes of 400 per site were proposed to allow for the collection of a sufficient number of specimens containing relatively low-prevalence drugs in the driving population; i.e., opiates, PCP and amphetamine/methamphetamine. If the study were designed to test the effectiveness of the onsite devices for marijuana and cocaine only, a smaller sample size would have been sufficient. Based on previous studies, we expected drug positive rates for DUI arrestees of approximately $10 \%$ to $15 \%$, yielding 40 to 60 drug positive participants per site. However, previous studies indicated that users of opiates and amphetamines/methamphetamines occur in only $1 \%$ to $2 \%$ of the sample. It was believed that the sample size of 400 per site (or 800 total) would provide 8 to 16 specimens on which to test the reliability of the devices for these drugs. However, as will be 
discussed later, the drug positive rate for this study was much higher than anticipated and provided a larger sample on which to evaluate the devices.

Specimen handling procedures. CHT supplied urine collection kits. Each kit contained the following:

$60 \mathrm{~mL}$ inert plastic collection bottles containing fluid tight, leak proof, self-sealing specimen bags.

$\square$ Each bag contained a liquid absorbing packet and specimen labels

ISA trained collectors at each site in the proper collection, handling, and shipment of urine specimens. All specimens were treated as biohazards during collection, handling, and shipment. All urine collection supplies such as latex gloves, indelible markers, manifests, labels, disposable laboratory coats, and safety glasses were provided to the data collection team as part of this contract (See Appendix A: Research and Data Collection Guidelines).

Law enforcement officials and analysts were given specific instructions to follow manufacturers' protocols explicitly and not to deviate from their procedures. The research team provided the research analysts a test result sheet to record the identification of the on-site device, sample identification, date and time of analysis, test results, his/her initials, and any additional comments. A brief rating form was also included for recording the police officers' subjective assessment of each device (see the dimensions listed under "data collection procedures" below).

CHT provided each site with shipping boxes; pre-printed shipping labels; and "bill recipient," overnight courier shipment forms. The research analysts shipped the specimens to CHT via overnight courier periodically. Upon receipt, CHT assigned the specimens a unique identification number reserved for specimens from this project. All specimens were stored frozen. For testing, CHT thawed the specimens and removed the liquid, usually $1 \mathrm{~mL}$ volume, for each confirmation test.

Data collection procedures. Data collection in Nassau County began in November 1998 and was completed in November 1999. In Houston, the data collection began October 1998 and was completed in July 1999. Data collection occurred on Friday and Saturday nights from 10:00 pm to 6:00 am. All individuals arrested for a suspected DUI offense and processed through the central testing facilities at each site were eligible to participate in the project. Written, informed consent was obtained from each participant. Participants were informed that their sample would be collected anonymously and used to assess the effectiveness of on-site drug testing devices. 
Research and police staff emphasized that the results of the tests would not be used against participants in any legal proceedings.

In Houston, seventy-seven percent (77\%) of the 975 arrestees eligible to participate were approached to participate. The remaining $23 \%$ were unable to provide consent due to advanced inebriation or language barriers. Of the 751 arrestees asked to participate, 53\% agreed and provided urine samples. The participation rate in Nassau County was higher. Of the arrestees asked to participate, approximately $79 \%$ agreed. The higher participation rate in Nassau County was due primarily to the fact that the Central Testing (police) staff approached a select sample of arrestees - those believed to be more likely to provide consent (typically those that complied with the DUI processing requirements and those that were not belligerent).

Each urine sample received a complete drug test with each of the five devices (so that officers had equal experience with each device). The sequence in which the devices were used was rotated. For example, Sample 1 was tested first with Triage ${ }^{\circledR}$, then TesTcup ${ }^{\circledR}$, AccuSign ${ }^{\circledR}$, Rapid Drug Screen ${ }^{\circledR}$, and TesTstik $\circledast$ in that order. Sample 2 was tested first with TesTcup $₫$, then AccuSign ${ }^{\circledR}$, Rapid Drug Screen $®$, TesTstik ${ }^{\circledR}$, and finally Triage ${ }^{\circledR}$. A police officer always conducted the testing with the first device in the sequence and the research analyst conducted the drug testing with the remaining four devices. After the officer completed the testing and recorded the results, s/he completed a rating form assessing the devices on five elements (ease of use, time needed to conduct the test, need for specimen handling, readability of results, usefulness of the test for routine DUI evaluation). Each element was rated on a five-point scale with " 5 " being the most positive response. If the urine sample tested positive for any of the five drugs on any of the five devices, the sample was sent to the CHT for GC/MS confirmation. In addition, as indicated earlier, $5 \%$ of the samples that tested negative on all five devices were also sent for GC/MS confirmation.

Confirmation testing procedures. CHT performed MS confirmations for all drugs presumptively identified as positive by any of the devices. In addition, $5 \%$ of the samples that tested negative (drug free) were randomly selected for confirmation testing. For each confirmation test, GC/MS confirmation cutoff sensitivities at lower concentrations than those of the federal standards (DOT, 1992; DHHS, 1993) were established. A summary of confirmation methods and testing limits used in this study can be found in Appendix B: Confirmation Testing Procedures. 


\section{RESULTS}

\section{Study Participants}

The research team collected demographic data for 783 of the 800 individuals who participated in the study. These data are presented in Table 3. The overwhelming majority $(93 \%)$ of the individuals who agreed to participate were male. This percentage differed slightly by site with females accounting for $4 \%$ of the participants in Nassau County and $6 \%$ in Houston. The percentage of males in the sample was comparable to the percentage of males in the arrest data from both Nassau County and Houston, although the percentage of males was somewhat higher in the study sample. The average age of the participants was 32 years and ranged from 17 years of age to 72 years of age. The mean age and age range were nearly identical in Nassau County and Houston and matched the 1999 arrest data in Nassau County. (Arrest data from Houston were not available). Caucasian participants comprised $45 \%$ of the study participants with Hispanic participants comprising 40\%, African Americans $11 \%$ and Asians $2 \%$. For the remaining $2 \%$ of participants, race information was not obtained. Expected differences were found between Nassau County and Houston with regard to Hispanic participants. In Houston, Hispanic participants comprised $57 \%$ of the sample (with Caucasians comprising 26\%). In Nassau County, Hispanics accounted for $24 \%$ of the participants, with Caucasians comprising $64 \%$.

Table 3

Demographic Characteristics of Study Participants

\begin{tabular}{|l|l|l|l|}
\hline & Nassau County & Houston & Total \\
\hline Mean Age & 32 & 32 & 32 \\
\hline Gender (\%*) & & & \\
\hline Male & $94 \%$ & $92 \%$ & $93 \%$ \\
\hline Female & $6 \%$ & $4 \%$ & $5 \%$ \\
\hline Unknown & $0 \%$ & $4 \%$ & $2 \%$ \\
\hline Ethnicity (\%*) & & & \\
\hline White & $64 \%$ & $26 \%$ & $45 \%$ \\
\hline African American & $11 \%$ & $11 \%$ & $11 \%$ \\
\hline Latino/Hispanic & $24 \%$ & $57 \%$ & $40 \%$ \\
\hline Asian & $1 \%$ & $3 \%$ & $2 \%$ \\
\hline Other & $<1 \%$ & $0 \%$ & $<1 \%$ \\
\hline Unknown & $0 \%$ & $5 \%$ & $2 \%$ \\
\hline
\end{tabular}

* Total may not add to $100 \%$ due to rounding 


\section{On-Site Device Results and MS Confirmations}

In total, 288 of the 800 cases $(36 \%)$ tested positive for at least one of the five drugs on at least one of the on-site devices. MS confirmations were conducted on 322 cases (40\%). These cases included the random sample of thirty-four cases that tested negative on all five devices. Data are summarized by drug and reported as false positive results, false negative results, and unconfirmed positive results. There are a number of ways to calculate the percentages of false positive and false negative results. We have adopted the conventional approach of calculating the percentages by using the entire sample of 800 cases as the denominator for each drug by each device. Percents are truncated to two decimal places.

Definitions. A false positive was recorded when the device indicated a positive result, but no drug(s) or metabolites were detected in the MS confirmation at a sufficient concentration to explain the result (for example, the result from Device A was positive for PCP, but the MS result for PCP was negative).

However, defining this category for the drug classes other than PCP required several considerations. The on-site devices are immunoassay-based tests with antibodies designed to react to a specific drug metabolite (e.g., morphine) within a drug class (e.g., opiates). The target metabolite for PCP is PCP, for cocaine is benzoylecgonine (BZE) and the target metabolite for marijuana is THC-COOH. With the analysis of opiates and amphetamines, there are other drugs within these drug classes that have similar chemical structures and the antibodies in the on-site devices have cross reactivity to these analogs. This reactivity varies with the antibody, analog, and with the devices. The extent to which these related drugs contribute to the response of the on-site device depends on the specific cross reactivity of the antibody in that device. The results presented below describe the false positive percentages for those cases in which the devices indicated a positive result for a drug class (e.g., amphetamines), but no drugs or metabolites were detected in the confirmation.

False negative results were assigned to those results where the device tested negative, but the sample contained drug concentrations greater than or equal to the device screening cutoff (for example, Device B result was negative for cocaine, but the MS result was greater than or equal to $300 \mathrm{ng} / \mathrm{mL}$ ). We categorized the false negative samples into two groups: 1) those in which the MS confirmation concentration was greater than the screening cutoff and 2) those in which the 
MS confirmation was greater than the DOT/DHHS confirmation cutoff. Category 1 is the most important. As noted earlier, all of the devices are designed to screen for the presence of the target drugs at the DOT/DHHS screening cutoff criteria. The second criterion, the DOT/DHHS MS confirmation, is the cutoff at which the MS confirms the presence of specific drug analytes. For some drugs, these concentrations are lower than the screening concentrations. These cutoff concentrations can be found in Table 4 .

The term Unconfirmed Positive is used to describe those cases where the device result was positive, but the concentration of target drug(s) or metabolites in the urine, as determined by MS, was below the DOT/DHHS confirmation cutoff. For example, the result for Device $\mathrm{C}$ was positive for PCP, but the MS result for PCP was $10 \mathrm{ng} / \mathrm{mL}$. The drug was present in the urine, but the concentration was less than the DOT/DHHS MS confirmation cutoff of $25 \mathrm{ng} / \mathrm{mL}$.

Table 4

Screening and MS Cutoff Concentrations

\begin{tabular}{|l|c|c|}
\hline & $\begin{array}{c}\text { On-Site Device and } \\
\text { DOT/DHHS Screening Cutoff } \\
\mathrm{ng} / \mathrm{mL}\end{array}$ & $\begin{array}{c}\text { DOT/DHHS } \\
\text { MS Confirmation criteria } \\
\mathrm{ng} / \mathrm{mL}\end{array}$ \\
\hline $\begin{array}{c}\text { CANNABINOIDS } \\
\text { THC-COOH }\end{array}$ & 50 & 15 \\
\hline $\begin{array}{c}\text { COCAINE } \\
\text { Cocaine } \\
\text { BZE }\end{array}$ & 300 & 150 \\
\hline $\begin{array}{c}\text { AMPHETAMINES } \\
\text { Amphetamine } \\
\text { Methamphetamine }\end{array}$ & 1000 & 150 \\
\hline $\begin{array}{c}\text { OPIATES* } \\
\text { Morphine }\end{array}$ & & 500 \\
Codeine & 300 & 500 \\
\hline $\begin{array}{c}\text { PHENCYLIDINE } \\
\text { PCP }\end{array}$ & & 300 \\
\hline
\end{tabular}

*Recently changed to $2,000 \mathrm{ng} / \mathrm{mL}$ screen and confirmation (DHHS, 1997).

\section{False Positive Results}

Table 5 presents the false positive percentages by device based on the total number of tests conducted $(n=800)$ for that drug with each device. As indicated above, these data include only those cases in which the device's positive result was explained by the presence of a sufficient 
concentration of one or more of the drugs or metabolites described in the MS confirmation methods (see Appendix B: Confirmation Testing Procedures).

Table 5

On-Site Device False Positive Results* as \% of All Samples Analyzed (n=800)

\begin{tabular}{|l|c|c|c|c|c|}
\hline & THC-COOH & Cocaine/BZE & $\begin{array}{c}\text { Amphetamines } \\
(* *)\end{array}$ & $\begin{array}{c}\text { Opiates } \\
(* * *)\end{array}$ & PCP \\
\hline Triage $®$ & 0.00 & 0.00 & 1.75 & 0.12 & 0.62 \\
\hline TesTcup $®$ & 0.00 & 0.00 & 0.25 & 0.25 & 0.75 \\
\hline AccuSign $®$ & 0.25 & 0.12 & 0.25 & 0.25 & 1.50 \\
\hline Rapid Drug Screen $®$ & 0.12 & 0.12 & 0.25 & 0.25 & 0.75 \\
\hline TesTstik $®$ & 0.00 & 0.00 & 0.12 & 0.25 & 0.62 \\
\hline
\end{tabular}

*Analytes not detected by MS

** \% Adjusted for the presence of methylenedioxymethamphetamine (MDMA/'Ecstasy")

*** \% Adjusted for the presence of hydromorphone/hydrocodone

THC-COOH. Two hundred and eight samples were submitted for confirmation THC$\mathrm{COOH}$ testing. One hundred and seventy-two of these samples tested positive on one or more of the on-site devices for THC-COOH. The remaining samples were negative samples. Only two of the 172 samples that tested positive on one or more on-site devices were negative by MS. Both samples were false positive results with AccuSign ${ }^{\circledR}(0.25 \%)$. One of the two samples $(0.12 \%)$ was a false positive result with Rapid Drug Screen ${ }^{\circledR}$.

Cocaine. One hundred and sixty-three samples were submitted for MS cocaine and metabolite (BZE) testing. One hundred and twenty-four of the samples tested positive on one or more of the on-site devices for BZE and the remaining were negative samples. Only one of the 163 samples that tested positive by the devices was negative by MS. That sample produced a false positive result with both AccuSign® $(0.12 \%)$ and Rapid Drug Screen ${ }^{\circledR}(0.12 \%)$.

Amphetamines. Seventy-seven samples were submitted for MS analysis of amphetamines. Thirty-nine of the samples tested positive on one or more of the on-site devices for amphetamines and the remaining samples were negative samples. Of the thirty-nine samples that tested positive using the on-site devices, only six had MS measurable concentrations of amphetamine, methamphetamine or phentermine (the target analytes). The false positive rates, adjusted for the 
potential effects of MDMA (see Unconfirmed Positives below), were as follows: Triage® 1.75\%; TesTcup® 0.25\%; AccuSign ${ }^{\circledR} 0.25 \%$; Rapid Drug Screen ${ }^{\circledR} 0.25 \%$; and TesTstik ${ }^{\circledR} 0.12 \%$.

Opiates. Seventy-seven samples were submitted for MS analysis of opiates. Thirty-eight of the samples tested positive on one or more of the on-site devices for opiates and the remaining were negative sample challenges. Of the thirty-eight samples that tested positive, only nineteen had measurable concentrations of total morphine or codeine by MS. However, hydrocodone and hydromorphone (see Unconfirmed Positives below) were found in nearly all the samples. The opiate false positive rates (adjusted for the presence of hydromorphone and hydrocodone) were as follows: Triage ${ }^{\circledR} 0.12 \%$; TesTcup® $0.25 \%$; AccuSign $(8) 0.25 \%$; Rapid Drug Screen® 0.25\%; and TesTstik® $0.25 \%$.

PCP. Seventy-five samples were submitted for MS analysis of PCP. Thirty-eight of the samples tested positive on one or more of the on-site devices and the remaining samples were negative samples. Of the thirty-eight samples that tested positive, twenty-three contained measurable concentrations of PCP by MS. The false positive rates were as follows: Triage $®$ 0.62\% $(n=5) ;$ TesTcup® 0.75\% $(n=6)$; AccuSign $® 1.50 \%(n=12) ;$ Rapid Drug Screen® $0.75 \%(n=6)$; and TesTstik ${ }^{\circledR} 0.62 \%(n=5)$. Four samples tested positive with all of the devices and a fifth sample tested positive with four of the five devices.

\section{False Negative Results}

False negative results were assigned to those results where the device tested negative, but the sample contained the target drug at a concentration above the device screening cutoff. This is an important category of errant results because it represents the DUI arrestees who had significant concentrations of drugs in their urine, but who would not have been identified using the device results. In addition, these are cases that may not have been prosecuted for driving under the influence of drugs because of the results. Table 6 presents two sets of the false negative results. The first set of results is based on the DOT/DHHS screening cutoff concentrations and the second set is based on the DOT/DHHS MS confirmation cutoff. There were no false negatives using any device for the thirty-four samples that tested negative on all five tests for all five drugs. False negative results were obtained, however, on those samples that tested negative on some, but not all, of the devices for a given drug. 


\section{Table 6}

On-Site Devica False Negative Results as \% of All Samples Analyzed (n=800) Drug Present in Concentrations Greater than the Screening Cutoff

\begin{tabular}{|l|c|c|c|c|c|}
\hline & THC-COOH & Cocaine/BZE & Amphetamines & Opiates & PCP \\
\hline Triage $®$ & 0.25 & 0.25 & 0.00 & 0.00 & 0.00 \\
\hline TesTcup-5® & 0.25 & 0.00 & 0.00 & 0.12 & 0.25 \\
\hline AccuSign $®$ & 0.12 & 0.12 & 0.00 & 0.00 & 0.00 \\
\hline Rapid Drug Screen $\AA$ & 0.37 & 0.12 & 0.00 & 0.00 & 0.00 \\
\hline TesTstik ${ }^{\circledR}$ & 0.25 & 0.12 & 0.00 & 0.00 & 0.00 \\
\hline
\end{tabular}

On-Site Device False Negative Results as \% of All Samples Analyzed ( $n=800)$ Drug Present in Concentrations Greater than the MS Confirmation Cutoff

\begin{tabular}{|l|c|c|c|c|c|}
\hline & THC-COOH & Cocaine/BZE & Amphetamines & Opiates & PCP \\
\hline Triage ${ }^{*}$ & 0.50 & 0.37 & 0.00 & 0.00 & 0.00 \\
\hline TesTcup-5® & 0.87 & 0.25 & 0.00 & 0.12 & 0.25 \\
\hline AccuSign ${ }^{\circledR}$ & 0.25 & 0.12 & 0.00 & 0.00 & 0.00 \\
\hline Rapid Drug Screen ${ }^{\circledR}$ & 0.37 & 0.12 & 0.00 & 0.00 & 0.12 \\
\hline TesTstik® & 0.75 & 0.25 & 0.00 & 0.00 & 0.00 \\
\hline
\end{tabular}

THC-COOH. A number of samples that tested negative on one or more devices contained more than $50 \mathrm{ng} / \mathrm{mL}$ of THC-COOH by MS. Using this screening criterion, the false negative rates were as follows: Triage ${ }^{\circledR} 0.25 \%(n=2)$; TesTcup ${ }^{\circledR} 0.25 \%(n=2)$; AccuSign ${ }^{\circledR} 0.12 \%(n=1)$; Rapid Drug Screen® 0.37\% $(n=3)$; and TesTstik ${ }^{\circledR} 0.25 \%(n=2)$. Additional samples tested negative on one or more devices that contained greater than $15 \mathrm{ng} / \mathrm{mL}$ of THC-COOH by MS. Using this DOT/DHHS MS confirmation criterion, the false negative rates were as follows: Triage ${ }^{\circledR} 0.50 \%(n=4)$; TesTcup ${ }^{\circledR} 0.87 \%(n=7)$; AccuSign ${ }^{\circledR} 0.25 \%(n=2)$; Rapid Drug Screen ${ }^{\circledR}$ $0.37 \%(n=3)$; and TesTstik ${ }^{\circledR} 0.75 \%(n=6)$. There did not appear to be a pattern for the samples that were not detected by the devices. Concentrations varied from $17 \mathrm{ng} / \mathrm{mL}$ to $130 \mathrm{ng} / \mathrm{mL}$ and no sample in the false negative category tested negative on all five of the devices.

Cocaine. Using the criterion that a false negative is any sample that tested negative with a device, but contained more than $300 \mathrm{ng} / \mathrm{mL}$ (the screening cutoff) of BZE (the target metabolite) by MS, the false negative rates were as follows: Triage ${ }^{\circledR} 0.25 \%(n=2)$; TesTcup ${ }^{\circledR} 0.00 \%(n=0)$; AccuSign® 0.12\% $(\mathrm{n}=1)$; Rapid Drug Screen® 0.12\% $(\mathrm{n}=1)$; and TesTstik® 0.12\% $(\mathrm{n}=1)$. These rates were adjusted to reflect the following cross reactivities to cocaine (that is, there were cases in which the sample contained sufficient concentrations of the parent drug cocaine in addition 
to BZE to trigger a positive response, but did not): Triage ${ }^{\circledR} 40 \%$; TesTcup® ${ }^{\circledR} \%$; AccuSign® 60\%; Rapid Drug Screen® 28\%; and TesTstik® 4\%. Additional samples tested negative on one or more devices that contained more than $150 \mathrm{ng} / \mathrm{mL}$ (the MS confirmation cutoff) of BZE (or equivalent) by MS. Using this DOT/DHHS criterion, the false negative rates were as follows: Triage ${ }^{\circledR} 0.37 \%(n=3)$; TesTcup ${ }^{\circledR} 0.25 \%(n=2)$; AccuSign $® 0.12 \%(n=1)$; Rapid Drug Screen® $0.12 \%(\mathrm{n}=1)$; and TesTstik ${ }^{\circledR} 0.25 \%(\mathrm{n}=2)$. There were too few false negative results to determine if there was a pattern in the discrepancies.

Amphetamines. There were no false negative amphetamine results among the thirty-four samples that tested negative on all five devices. Nor were there any false negative results using the DOT/DHHS screening or MS confirmation criteria for samples that obtained mixed results from the devices for amphetamines.

Opiates. One sample tested negative using TesTcup ${ }^{\circledR}(0.12 \%)$ that was a false negative result using either the DOT/DHHS screening or MS confirmation criteria for reporting a sample positive for opiates. No false negative errors were found with the other four devices.

PCP. Two samples tested negative using TesTcup ${ }^{\circledR}(0.25 \%)$ and one with Rapid Drug Screen® $(0.12 \%)$ that were false negative results using either the DOT/DHHS screening or MS confirmation criteria for reporting a sample positive for PCP. No false negative errors were reported from the other devices.

\section{Unconfirmed Positive Results - Based On Analytical Cutoff}

A major consideration in evaluating the accuracy and reliability of the devices was the selection of a comparison standard. Numerous studies have been published to assess the accuracy and reliability of on-site drug screening test devices (Buchan, 1997; Crouch, 1997; 1998; Ferrara, 1994; Hwang, 1994; Koch, 1994; Towt, 1995). The basic design of many of these studies was similar to the study reported here. On-site test results were compared to test results obtained from one or more alternate methods. However, usually these caparisons were made based on laboratory results using the DOT/DHHS testing guidelines.

In this section we present the results of this study based on those guidelines - specifically the MS confirmation concentration guidelines. Unconfirmed positive results were those results in which the device(s) tested positive, but compared to the DOT and DHHS confirmation 
guidelines, would have confirmed negative because the MS drug concentration was less than the higher confirmation standard (DOT and DHHS). This is an important category of samples because it represents those DUI arrestees who had drugs in their urine, but who would have been reported as drug free using these widely accepted standards. It also is the category to which many of the "False Positive" results in previous studies should have been assigned. Table 7 presents the percentage of unconfirmed positive results by device based on the DOT/DHHS confirmation criteria.

\section{Table 7}

Unconfirmed Positive Results as \% of All Samples Analyzed (n=800) Drug Present by MS Below the DOT/DHHS Confirmation Criteria

\begin{tabular}{|l|c|c|c|c|c|}
\hline & THC-COOH & Cocaine/BZE & Amphetamines & Opiates & PCP \\
\hline Triage $®$ & 1.12 & 0.50 & 0.12 & 0.37 & 0.25 \\
\hline TesTcup® & 1.12 & 0.50 & 0.12 & 0.25 & 0.25 \\
\hline AccuSign® & 1.00 & 1.37 & 0.12 & 0.37 & 0.37 \\
\hline Rapid Drug Screen $®$ & 1.00 & 1.37 & 0.12 & 0.37 & 0.37 \\
\hline TesTstik® & 1.12 & 0.50 & 0.12 & 0.37 & 0.25 \\
\hline
\end{tabular}

THC-COOH. Of the hundred and seventy-two samples that tested positive on one or more of the on-site devices for THC-COOH, only two were negative by MS. However, several had MS concentrations of THC-COOH that were less than the $15 \mathrm{ng} / \mathrm{mL}$ DOT/DHHS MS confirmation standard. The unconfirmed positive results rates were as follows: Triage ${ }^{\circledR} 1.12 \%(\mathrm{n}=9)$; TesTcup ${ }^{\circledR} 1.12 \%(\mathrm{n}=9) ;$ AccuSign ${ }^{\circledR} 1.00 \%(\mathrm{n}=8)$; Rapid Drug Screen ${ }^{\circledR} 1.00 \%(\mathrm{n}=8)$; and TesTstik® $1.12 \%(n=9)$. There were seven samples that produced a positive result with all of the devices. The mean THC-COOH concentration of these seven samples was $10.33 \mathrm{ng} / \mathrm{mL}$. Only one contained less than $10 \mathrm{ng} / \mathrm{mL}$ of THC-COOH. Lowering the current cutoff by $1 / 2$ to $7.5 \mathrm{ng} / \mathrm{mL}$ for THC-COOH would result in the following unconfirmed positive results: Triage ${ }^{\circ} 0.25 \%(n=2)$; TesTcup ${ }^{\circledR} 0.25 \%(n=2)$; AccuSign $® 0.25 \%(n=2)$; Rapid Drug Screen ${ }^{\circledR} 0.12 \%(n=1)$; and TesTstikß $0.12 \%(\mathrm{n}=1)$.

Cocaine. Of the hundred and twenty-four samples that tested positive on one or more of the on-site devices for BZE, only one was negative by MS. However, fourteen had MS concentrations of BZE less than the $150 \mathrm{ng} / \mathrm{mL}$ DOT/DHHS MS confirmation standard. The unconfirmed positive rates were as follows: Triage ${ }^{\circledR} 0.50 \%(n=4)$; TesTcup® $0.50 \%(n=4)$; AccuSign ${ }^{\circledR} 1.37 \%(n=11)$; Rapid Drug Screen ${ }^{\circledR} 1.37 \%(n=11)$; and TesTstik $(0.50 \%(n=4)$. 
There were three samples that produced positive results on five devices. The mean BZE concentration of these unconfirmed positive samples was $86.57 \mathrm{ng} / \mathrm{mL}$. Lowering the current cutoff by $1 / 2$ to $75 \mathrm{ng} / \mathrm{mL}$ for BZE would result in the following unconfirmed positive rates: Triage ${ }^{\circledR} 0.00 \%(n=0)$; TesTcup ${ }^{\circledR} 0.00 \%(n=0)$; AccuSign $® 0.75 \%(n=6)$; Rapid Drug Screen $®$ $0.75 \%(n=6)$; and TesTstik ${ }^{\circledR} 0.00 \%(n=0)$.

Amphetamines. Of the thirty-nine samples that tested positive on one or more of the onsite devices for amphetamines, only six had MS measurable concentrations of amphetamine, methamphetamine or phentermine. One sample produced a positive result on all of the devices, had an MS concentration of amphetamine that was less than the $500 \mathrm{ng} / \mathrm{mL}$ DOT/DHHS MS standard, and could be classified as an unconfirmed positive result. The unconfirmed positive rate for all of the devices was $0.12 \%(\mathrm{n}=1)$. An additional sample contained more than $1,000 \mathrm{ng} / \mathrm{mL}$ of phentermine, tested positive on all of the devices, and could be classified as an unconfirmed positive result because DOT and DHHS do not include phentermine as a drug for confirmation. Only Rapid Drug Screen® publishes a device cross reactivity to phentermine (1\%).

Opiates. Of the thirty-eight samples that tested positive for opiates using the on-site devices, nineteen contained measurable concentrations of morphine or codeine by MS. However, three of these nineteen samples had MS concentrations of morphine and/or codeine that were lower than the $300 \mathrm{ng} / \mathrm{mL}$ DOT and DHHS MS standard and were classified as unconfirmed positive results. The unconfirmed positive rates were as follows: Triage ${ }^{\circledR} 0.37 \%(n=3)$; TesTcup ${ }^{\circledR} 0.25 \%$ $(\mathrm{n}=2)$; AccuSign ${ }^{\circledR} 0.37 \%(\mathrm{n}=3)$; Rapid Drug Screen ${ }^{\circledR} 0.37 \%(\mathrm{n}=3)$; and TesTstik ${ }^{\circledR} 0.37 \%(\mathrm{n}=$ 3). One sample tested positive on all of the devices and contained $115 \mathrm{ng} / \mathrm{mL}$ of codeine. Two additional samples did not test uniformly positive on the devices, contained no codeine, and had 32 and $277 \mathrm{ng} / \mathrm{mL}$, respectively, of morphine.

PCP. Of the thirty-eight samples that tested positive on the on-site devices, twenty-three had measurable concentration of PCP by MS and three had concentrations of PCP that were less than the $25 \mathrm{ng} / \mathrm{mL}$ DOT and DHHS standard. The unconfirmed positive rates were as follows: Triage ${ }^{\circledR} 0.25 \%(n=2)$; TesTcup ${ }^{\circledR} 0.25 \%(n=2)$; AccuSign ${ }^{\circledR} 0.37 \%(n=3)$; Rapid Drug Screen ${ }^{\circledR}$ $0.37(n=3)$; and TesTstik ${ }^{\circledR} 0.25 \%(n=2)$. Because the screen and MS confirmation concentrations are both $25 \mathrm{ng} / \mathrm{mL}$ for PCP, there is no obvious explanation for the errors. 


\section{Unconfirmed Positive Results - Based On Tested Drugs}

As discussed above, a major consideration in evaluating the accuracy and reliability of the devices was the selection of a comparison standard. Usually, on-site test results have been compared to laboratory results using the DOT/DHHS testing guidelines. In this section, we present the results of the current study based on the drugs tested in those guidelines. These unconfirmed positive results were those results in which the device(s) tested positive, but compared to the DOT and DHHS confirmation guidelines, would have been reported negative because the sample did not contain detectable concentrations of a DOT/DHHS MS target drug. Again, this is an important category of samples because these are arrestees who had drugs in their urine, but would have been reported as drug free using these widely accepted standards. This is the category to which many of the "False Positive" results in previous studies should have been assigned. Table 8 presents the percentage of unconfirmed positive results based on tested drugs by device.

\section{Table 8}

Unconfirmed Positive Results as \% of All Samples Analyzed ( $\mathbf{n = 8 0 0 )}$ Based on Target Drugs

\begin{tabular}{|l|c|c|c|c|c|}
\hline & THC-COOH & Cocaine/BZE & Amphetamines & Opiates & PCP \\
\hline Triage® & 0.00 & 0.00 & 3.75 & 2.25 & 0.62 \\
\hline TesTcup ${ }^{\circledR}$ & 0.00 & 0.00 & 2.25 & 2.37 & 0.75 \\
\hline AccuSign ${ }^{\circledR}$ & 0.25 & 0.12 & 2.25 & 2.37 & 1.50 \\
\hline Rapid Drug Screen ${ }^{\circledR}$ & 0.12 & 0.12 & 2.50 & 2.37 & 0.75 \\
\hline TesTstik® & 0.00 & 0.00 & 2.12 & 2.25 & 0.62 \\
\hline
\end{tabular}

THC-COOH, Cocaine, and PCP. Because the target analyte for the devices and the MS confirmation for these drugs are essentially the same, no difference was observed between the unconfirmed positive results based on tested drugs and the false positive rate presented earlier.

Amphetamines. Thirty-nine of the samples tested positive on one or more of the on-site devices for amphetamines and the remaining samples were negative samples. As indicated above, of the thirty-nine samples that tested positive using the on-site devices, only six had MS measurable concentrations of amphetamine, methamphetamine or phentermine (the target analytes). However, sixteen of the thirty samples that resulted in drug positive finding with the Triage ${ }^{\circledR}$ test contained 
methylenedioxymethamphetamine (MDMA), an illicit drug known by the street name "Ecstasy." Sixteen of eighteen TesTcup ${ }^{\circledR}$ and AccuSign ${ }^{\circledR}$ amphetamine positive samples contained MDMA, seventeen of nineteen Rapid Drug Screen ${ }^{\circledR}$ positive samples contained MDMA, and sixteen of seventeen TesTstik ${ }^{\circledR}$ positive samples contained MDMA. The cross reactivity of the devices to MDMA was as follows: Triage ${ }^{\circledR}, 30 \%$; TesTcup ${ }^{\circledR}, 50 \%$; AccuSign $®, 14 \%$; Rapid Drug Screen ${ }^{\circledR}$, $30 \%$; and TesTstik® 25\%. (This cross reactivity indicates the concentration of MDMA necessary in the sample for each device to cause a positive response). For example, the cross reactivity of TesTcup ${ }^{\circledR}$ to MDMA was $50 \%$. The screening cutoff concentration for amphetamine/ methamphetamine for all devices is $1000 \mathrm{ng} / \mathrm{mL}$. For MDMA to cause a positive response with the TesTcup $®$ device, a concentration of at least $2000 \mathrm{ng} / \mathrm{mL}$ of MDMA (twice that of the amphetamine cutoff) would be necessary. That is, TesTcup $®$ is $50 \%$ as sensitive to MDMA as it is to the target analyte (amphetamine or methamphetamine). MDMA was only qualitatively identified in the samples. Therefore, it is not possible to definitively predict whether the MDMA concentrations were sufficient to produce a positive result with each device. However, the sixteen samples that contained MDMA tested positive on all of the devices and, in many of the urine samples where it was identified, the MS response of MDMA exceeded the response of the 1,000 $\mathrm{ng} / \mathrm{mL}$ methamphetamine standard. Therefore, the presence of MDMA was the likely explanation for the positive result. Without taking into consideration these cross-reactivities (that is, positive on-site results which would not have been confirmed by MS using the standard confirmation methods), the unconfirmed positive rates for the target analytes (amphetamine, methamphetamine, and phentermine) were as follows: Triage $\AA 3.75 \%(n=30)$; TesTcup $(2.25 \%(n=18)$; AccuSign $® 2.25 \%(n=18)$; Rapid Drug Screen ${ }^{\circledR} 2.50 \%(n=20)$; and TesTstik ${ }^{\circledR} 2.12 \%(n=17)$. As discussed above, the false positive rates reported earlier, adjusted for the potential effects of MDMA, were as follows: Triage® 1.75\%; TesTcup ${ }^{\circledR} 0.25 \%$; AccuSign® $0.25 \%$; Rapid Drug Screen® 0.25\%; and TesTstik® $0.12 \%$.

Two additional Triage ${ }^{\circledR}$ false positive samples contained phenylpropanolamine, pseudoephedrine, or ephedrine. The cross reactivities of the devices to these over-the-counter drugs was quite low and not a likely explanation for a positive test result. However, this explanation cannot be ruled out as only qualitative MS analyses were performed for these drugs. 
Opiates. Seventy-seven samples were submitted for MS analysis of opiates. Thirty-eight of the samples tested positive on one or more of the on-site devices for opiates and the remaining were negative sample challenges. Of the thirty-eight samples that tested positive, only nineteen had measurable concentrations of total morphine or codeine by MS. However, all but one of the Triage ${ }^{\circledR}$ and all but two of the TesTcup ${ }^{\circledR}$, AccuSign $®$, Rapid Drug Screen ${ }^{\circledR}$, and TesTstik ${ }^{\circledR}$ positive opiate samples contained hydromorphone and hydrocodone at concentrations greater than $200 \mathrm{ng} / \mathrm{mL}$. Hydromorphone (available as a prescription pain medication Dilaudid®) is a metabolite of hydrocodone. Hydrocodone is also a prescription pain medication available as Vicadin ${ }^{\circledR}$, Lortab $\AA$, Lorset ${ }^{\circledR}$, and others. The cross reactivity of the devices to hydromorphone was: Triage ${ }^{\circledR}, 75 \%$; TesTcup ${ }^{\circledR}, 43 \%$; AccuSign ${ }^{\circledR}, 50 \%$; Rapid Drug Screen ${ }^{\circledR}$, not published; and TesTstik $®, 43 \%$. The cross reactivity of the devices to hydrocodone was as follows: Triage ${ }^{\circledR}$, not published; TesTcup ${ }^{\circledR}, 60 \%$; AccuSign ${ }^{\circledR}, 60 \%$; Rapid Drug Screen ${ }^{\circledR}, 6 \%$; and TesTstik ${ }^{\circledR}, 38 \%$. These cross reactivities indicate the concentration of hydrocodone or hydromorphone needed to produce a positive response for each device. The screening cutoff for morphine (the target analyte for opiates) for all devices was $300 \mathrm{ng} / \mathrm{mL}$. For hydromorphone to cause a positive response from the AccuSign ${ }^{\circledR}$ device, for example, a concentration of at least $600 \mathrm{ng} / \mathrm{mL}$ would be necessary because AccuSign $®$ had a $50 \%$ cross reactivity to hydrocodone. Both hydrocodone and hydromorphone were present in all of the samples. Therefore, the immunoresponse of each sample was equal to the combined effects of both drugs. Also, in many of the urine samples the estimated drug concentrations, based on their MS responses relative to morphine and codeine, were quite high. Further evidence that the positive on-site device results were attributable to hydromorphone and hydrocodone is found in the data. All the positive opiate samples that contained hydromorphone and/or hydrocodone were positive on all of the devices with only two exceptions. If the presence of hydrocodone and hydromorphone are not taken into consideration, the unconfirmed positive rates based on tested drugs (target analytes) rates were as follows: Triage ${ }^{\circledR} 2.25 \%(n=18)$; TesTcup ${ }^{\circledR} 2.37 \%(n=19)$; AccuSign ${ }^{\circledR} 2.37 \%(n=19)$; Rapid Drug Screen® 2.37\% $(n=19)$; and TesTstik ${ }^{\circledR} .25 \%(n=18)$.

\section{Comparison of Officer Test Results and Research Analyst Test Results}

Results from the tests conducted by the officers were compared to results from the tests conducted by the research analysts to determine whether the devices performed differently when 
handled by the officers. Table 9 presents the results of those comparisons. Of the 4,000 tests performed with the devices used ( 5 devices $x 800$ samples), there were forty-seven tests in which one of the devices resulted in an error (i.e., a result that was not confirmed by MS) and the other four devices performed accurately. Twenty-seven of those errors were the result of the research analysts performing the test and twenty of the errors were the result of the officers performing the tests. When the number of tests performed by the officers and the research analysts is taken into consideration, the error rate for the research analysts was $0.8 \%(27 / 3200)$. The error for the officers was $2.5 \%(20 / 800)$. One sample accounted for four of the errors made by the officers (i.e., the officer incorrectly recorded the results for four of the five drugs for one device). If that sample is removed from the analysis of the errors, the error rate for the officers drops to $2.0 \%$. More dramatic differences were found in comparisons across individual devices. As Table 9 indicates, officers had considerably higher percentages of errors for AccuSign ${ }^{\circledR}$, Rapid Drug Screen ${ }^{\circledR}$, and Triage ${ }^{\circledR}$ than the research analysts.

Table 9

Comparison of Research Analyst and Officer Errors by Device

\begin{tabular}{|c|c|c|}
\hline & $\begin{array}{c}\text { Research Analysts } \\
(\mathrm{n}=3200)\end{array}$ & $\begin{array}{l}\text { Officers } \\
(\mathrm{n}=800)\end{array}$ \\
\hline Triage ${ }^{\circledR}$ & $\begin{array}{c}1.7 \% \\
(11 / 640) \\
\end{array}$ & $\begin{array}{c}3.1 \% \\
(5 / 160) \\
\end{array}$ \\
\hline TesTcup-5® & $\begin{array}{c}0.9 \% \\
(6 / 640)\end{array}$ & $\begin{array}{c}0.6 \% \\
(1 / 160) \\
\end{array}$ \\
\hline AccuSign® & $\begin{array}{c}0.8 \% \\
(5 / 640)\end{array}$ & $\begin{array}{r}3.8 \% \\
(6 / 160) \\
\end{array}$ \\
\hline Rapid Drug Screen ${ }^{\circledR}$ & $\begin{array}{c}0.5 \% \\
(3 / 640) \\
\end{array}$ & $\begin{array}{c}4.4 \% \\
(7 / 160) \\
\end{array}$ \\
\hline TesTstik® & $\begin{array}{c}0.3 \% \\
(2 / 640) \\
\end{array}$ & $\begin{array}{c}\mathbf{0 . 6 \%} \\
(1 / 160) \\
\end{array}$ \\
\hline TOTAL & $\begin{array}{c}\mathbf{0 . 8 \%} \\
(27 / 3200) \\
\end{array}$ & $\begin{array}{c}2.5 \% \\
(20 / 800)\end{array}$ \\
\hline
\end{tabular}

\section{Drug Positive Rate}

Although this study was not a prevalence study (such a study would have required much more stringent sampling procedures), a substantial number (36\%) of the 800 drivers who were arrested for suspected DUI screened positive for one or more drugs in their urine using the on- 
site devices. This rate is considerably higher than rates found in previous studies. The results of the on-site devices by drug are presented in Table 10 .

Table 10

Percentage of DUI Suspects Found Positive by On-Site Devices*

\begin{tabular}{|c|c|c|c|c|c|}
\hline & THC & COC & PCP & AMP & MOR \\
\hline Nassau County & $\begin{array}{c}27.3 \% \\
(\mathrm{n}=109)\end{array}$ & $\begin{array}{c}15.3 \% \\
(\mathrm{n}=61)\end{array}$ & $\begin{array}{c}3.5 \% \\
(\mathrm{n}=14)\end{array}$ & $\begin{array}{c}8.8 \% \\
(\mathrm{n}=35)\end{array}$ & $\begin{array}{c}4.3 \% \\
(\mathrm{n}=17)\end{array}$ \\
\hline Houston & $\begin{array}{c}16.0 \% \\
(\mathrm{n}=64)\end{array}$ & $\begin{array}{c}15.8 \% \\
(\mathrm{n}=63)\end{array}$ & $\begin{array}{c}5.8 \% \\
(\mathrm{n}=23)\end{array}$ & $\begin{array}{c}1.8 \% \\
(\mathrm{n}=7)\end{array}$ & $\begin{array}{c}5.5 \% \\
(\mathrm{n}=22)\end{array}$ \\
\hline Total & $\begin{array}{c}21.6 \% \\
(\mathrm{n}=173)\end{array}$ & $\begin{array}{c}15.5 \% \\
(\mathrm{n}=124)\end{array}$ & $\begin{array}{c}4.6 \% \\
(\mathrm{n}=37)\end{array}$ & $\begin{array}{c}5.25 \\
(\mathrm{n}=42)\end{array}$ & $\begin{array}{c}4.9 \\
(\mathrm{n}=39)\end{array}$ \\
\hline
\end{tabular}

* Not a prevalence rate. The drug positive counts present a drug positive rate greater than the overall rate reported above, but some of the samples tested positive for more than one drug these are only counted once for the purposes of the total drug positive rate.

Although THC showed the highest drug positive rate, drug use patterns differed in each site. In Nassau County, the drug positive rate for THC (27.3\%) was substantially higher than the drug positive rate for any other drug - cocaine had the next highest positive rate with $15.3 \%$. By contrast, in Houston, the drug positive rates for THC (16.0\%) and cocaine (15.3\%) were similar. In addition, the drug positive rate for amphetamines in Nassau County (8.8\%), as indicated by the devices, was nearly five times as high as in Houston (1.8).

The overall drug positive rate was reduced when the MS confirmation data were considered. Of the 288 samples that tested positive on one or more of the devices, 233 were confirmed by MS using the DOT/DHHS guidelines for confirmations (standard confirmation cutoff concentrations, restricted drug class, etc.) for a confirmed drug positive rate of $29 \%$. In many cases, the samples tested positive for more than one drug. However, as described above, many of the samples that tested positive on the drug testing devices obtained negative confirmations because the drug concentrations were below the DOT/DHHS cutoffs or the samples tested positive for drugs not included in the standard MS panel (e.g., MDMA, hydrocodone, hydromorphone, etc.). In the cases of THC and cocaine for example, 24 of the 28 
samples that were negative by MS contained measurable drug concentrations. The drug positive rate that includes samples testing positive below the DOT/DHHS cutoff concentrations or for drugs not commonly tested during MS confirmations was $33 \%$.

\section{DRE Evaluations}

In addition to the data from the on-site devices and the MS confirmations, we also collected data, when available, from the DRE evaluations. Officers conducted DRE evaluations in forty-one cases. Results from the DRE evaluations and on-site devices were compared to assess how the devices might be used in conjunction with the DRE evaluations. The results are based on a limited number of DRE evaluations and are not designed to assess the accuracy of the DRE evaluations. We expected to find discrepancies between the DRE evaluations and the onsite devices for a number of reasons. First, the DRE evaluations are designed to assess driving impairment from drugs while the on-site devices detect the presence of the drug or metabolite in urine. Given the number of days a drug metabolite may be detected in urine, it is entirely possible that the on-site devices could detect the presence of a drug and DRE evaluation indicate no evidence of impairment from that drug at the time of arrest because drug metabolites may be detected in urine days or weeks after use. In addition, decisions made by law enforcement officers to charge a suspect with driving under the influence of a drug are not made casually and officers are likely to be extremely cautious about making those decisions. Finally, it is also possible that a suspect may show impairment from a drug prior to the drug metabolite appearing in the urine and being detected by the devices.

THC-COOH. In twenty-two of the forty-one cases in which the DRE evaluation was conducted, the officer indicated that the arrestee was driving under the influence of THC. In twenty of those cases $(91 \%)$, the on-site devices and MS tests confirmed those findings. In two cases, the DRE findings were not consistent with the on-site devices or MS confirmation. However, in one of those cases, the DRE evaluation also indicated that the arrestee was driving under the influence of cocaine. Both the devices and MS test confirmed this finding. There were also six additional cases in which the devices and MS confirmation indicated the presence of THC, which was not indicated on the DRE evaluation. In one of those cases, the DRE evaluation indicated the presence of PCP, which was confirmed by both the devices and the MS 
confirmation. These results suggest that, although the THC metabolite was present in urine at the time of arrest, no driving impairment was apparent from that drug. This finding is due largely to the fact that drug metabolites may be found in urine days (or sometimes weeks) after the drug is taken (when it is no longer a factor in impairment).

Cocaine. Officers noted the presence of cocaine in nine cases, eight $(89 \%)$ of which were consistent with the on-site devices and confirmed by MS tests. In the one case that was not confirmed by MS, the presence of cocaine below the DHHS cutoff concentration was indicated and Triage ${ }^{\circledR}$ also indicated a drug positive for cocaine. An additional six cases resulted in drug positive findings on both the devices and MS confirmation but negative DRE evaluations. However, in four of those cases the DRE evaluation indicated the presence of other drugs, which were also identified by the devices and MS confirmation.

Amphetamines. Two cases resulted in positive findings for amphetamines on the DRE evaluation. In neither case, however, did the devices or MS confirmation indicate the presence of amphetamines. In one of those cases, the DRE evaluation indicated the presence of PCP as well, which was confirmed by the devices and the MS test. In the second case, the devices and MS confirmation also noted the presence of cocaine, although the DRE evaiuation for that drug was negative.

Opiates. There were five cases that resulted in positive DRE evaluations for opiates. Two of those cases were confirmed by the devices and MS tests. In two additional cases, the devices indicated the presence of opiates and the MS tests confirmed the presence of hydrocodone and hydromorphone. DRE evaluations resulted in negative findings for opiates in three cases in which the devices and the MS confirmations indicated the presence of opiates. In two of those cases, the DRE evaluation resulted in positive findings for THC, which were also confirmed by the devices and MS confirmation.

PCP. DRE evaluations noted the presence of PCP in five cases, all of which were confirmed by the devices and MS confirmation. There were five additional cases in which the DRE indicated a negative finding for PCP and the devices and MS confirmations indicated positive results. In three of those cases, the DRE evaluation indicated the presence of THC, which was confirmed by the devices and MS. 


\section{Officer Ratings and Interviews}

As indicated in the Methods section, the law enforcement officers who participated in the field test rated each device. These ratings were not intended to make comparative assessments of the specific devices, but rather to provide information on the officer's subjective judgment of the device as it was being used. The ratings were not meant to indicate that one or more devices were superior. Indeed, as indicated below, one of the devices rated most favorably by the officers was also one of the devices that produced the greatest percentage of errors for the officers.

The results of the ratings can be found in Table 11. AccuSign ${ }^{\circledR}$ received the highest rating across each element followed by Rapid Drug Screen®, TesTcup ${ }^{\circledR}$, TesTstik®, and Triage ${ }^{\circledR}$. During the follow-up interviews with a sample of the officers, they indicated that the devices that required the least time and urine handling received more favorable ratings.

Table 11

Officer Ratings

(5 Point Scale: 1=Least Favorable, 5=Most Favorable)

\begin{tabular}{|c|c|c|c|c|c|c|}
\hline & $\begin{array}{c}\text { Ease of } \\
\text { Use }\end{array}$ & $\begin{array}{c}\text { Time } \\
\text { Needed }\end{array}$ & $\begin{array}{c}\text { Need for } \\
\text { Specimen } \\
\text { Handling }\end{array}$ & $\begin{array}{c}\text { Readability } \\
\text { of Results }\end{array}$ & $\begin{array}{c}\text { Usefulness } \\
\text { of Devices } \\
\text { for Testing }\end{array}$ & Total \\
\hline Triage® & 2.34 & 1.72 & 2.42 & 3.01 & 2.43 & 2.38 \\
\hline TesTcup-5® & 3.05 & 2.91 & 2.70 & 3.28 & 3.14 & 3.02 \\
\hline AccuSign® ${ }^{\circledR}$ & 3.86 & 3.73 & 3.61 & 3.72 & 3.77 & 3.74 \\
\hline $\begin{array}{c}\text { Rapid Drug } \\
\text { Screen }{ }^{\circledR}\end{array}$ & 3.34 & 3.08 & 2.71 & 3.25 & 3.22 & 3.12 \\
\hline TesTstik $\circledR$ & 3.04 & 2.59 & 2.57 & 3.16 & 2.89 & 2.85 \\
\hline
\end{tabular}

The seventeen officers who participated in the follow-up interviews were also asked to comment generally on the use of the drug testing devices. The majority of officers believed that the devices could be used routinely in the traffic division and all of the officers interviewed believed there were benefits to using the devices. The most frequently noted benefits were that the devices could be used to provide quick results so that the officer has some indication if there were drugs in the arrestee's system and that the results could help reinforce the decisions the officers make in the field. Many of the officers, including DRE-trained and non-DRE-trained officers, felt the devices were ideal supplemental tools for the DRE program. One of the possible 
drawbacks mentioned by the officers was that some officers might rely. too much on the device results and not enough on the examination designed to determine impairment. Other drawbacks included: 1) officers' discomfort with handling urine; 2) the limited number of drug classes detected by the devices; and 3) questions about the accuracy of the device.

\section{DISCUSSION AND CONCLUSIONS}

The overall purpose of the study was to conduct a field assessment of the on-site drug detection devices to evaluate their performance as potentially useful tools for law enforcement. The study provided a number of substantive results in terms of the devices' technical performance, the reactions of law enforcement officers to conducting the tests, the additional information the devices can provide a DRE assessment, and the differences in performance of the devices when conducted by research analysts and law enforcement officers. In addition, an unexpected finding was the high percentage of drug positive samples among individuals suspected of driving under the influence. The drug positive rate found in this study was alarming and substantially higher than rates found in a study of drug use by fatally injured drivers (Terhune, 1992), though the two studies were evaluating entirely different samples.

Although the on-site devices were evaluated on several criteria, the primary evaluation was based on a comparison of the on-site device results with MS results. For each device and each drug, false positive and false negative rates were calculated. False Positive results were defined as cases in which the device indicated a positive result, but no drug(s) or metabolites were detected by MS. False Negative results were defined as cases where the devices tested negative but measurable concentrations of the drug analyte(s) were present in excess of the screening MS cutoff. In addition, we compared the results of the on-site kits to MS confirmations using the widely accepted confirmation guidelines for cutoff concentrations and target drugs. Unconfirmed Positive results were defined as those cases in which the devices tested positive, but would not have been confirmed as positive using the DOT/DHHS guidelines because either: 1) drugs other than the target analyte(s) for the devices were present or 2) the target analytes were present but at concentrations lower than the DOT/DHHS MS confirmation cutoffs. 
A number of patterns emerged from the comparisons between the results of the on-site devices and MS confirmations. First, the devices generated relatively few false positive results, particularly for THC-COOH, PCP, and cocaine/BZE. However, the unconfirmed positive rates were higher for amphetamines and opiates, attributable largely to the presence of drugs other than the target analyte(s) that had similar chemical structures. Rates for THC-COOH, cocaine/BZE and PCP were consistent with those expected using instrumented immunoassay screening. However, when testing for amphetamines, there were seventeen cases in which all five devices tested positive, but no amphetamine or methamphetamine was found by MS. The unconfirmed positive rates varied from 2.12 to $3.75 \%$. A similar pattern was seen with the opiates where rates varied from $2.25 \%$ to $2.37 \%$. When the data from these two drug classes were adjusted for the presence of MDMA, hydromorphone, and hydrocodone, the false positive rates for amphetamines and opiates fell to less than $2 \%$ and less than $0.3 \%$, respectively. These lower rates are consistent with those anticipated using instrumented immunoassays. However, the unconfirmed positive rates for target drugs clearly indicate that the confirmation battery for opiates and amphetamines needs to be expanded to include additional drugs to be useful in detecting drugs in arrested drivers.

The unconfirmed positive rates based on drug concentration, were less than $1.37 \%$. Rates between devices were essentially equal for THC-COOH, amphetamines, opiates and PCP. When testing for BZE, however, AccuSign ${ }^{\circledR}$ and Rapid Drug Screen ${ }^{\circledR}$ had higher rates than the other devices. Reducing the DOT/DHHS confirmation cutoff by one half reduces the unconfirmed positive rates for $\mathrm{THC}-\mathrm{COOH}$ to less than $0.25 \%$ for all devices. For BZE testing, decreasing the confirmation cutoff reduced the rate to $0.0 \%$ for three of the five devices and to $0.75 \%$ for AccuSign $®$ and Rapid Drug Screen $®$.

False negative results were rare and the devices compared favorably across drug classes. When the false negative rates were calculated based on the immunoassay screening cutoff, only the false negative results for THC-COOH testing with Rapid Drug Screen ${ }^{\circ}$ exceeded $0.25 \%$. The devices also compared favorably across drug classes when the false negative rates were calculated based on the DOT/DHHS confirmation cutoffs. Only the false negative results for THC-COOH testing exceeded $0.50 \%$ and then only for TesTcup® and TesTstik®. All of the devices for all of the drug classes had false negative rates less than $0.87 \%$. 
The data from the devices and the MS testing clearly indicate that, when cutoff concentrations and additional drugs are taken into consideration, the devices were accurate in identifying positive samples and rarely failed to identify a driver who had the target drugs in his/her urine.

The officers who participated in the study generally favored the use of on-site devices in the enforcement of impaired driving laws. However, they cautioned that the use of these devices should not supplant the officer's judgment regarding impairment. Subjectively, officers rated the AccuSign ${ }^{\circledR}$ device to be the most favorable. From the DRE analyses, it is clear that the devices can provide law enforcement officers with information that may supplement the DRE evaluation. It should be remembered that test results from the devices can indicate only the presence or absence of drugs in the urine and not the extent of impairment caused by the drugs.

One of the key features of this study was that it was a field test, whereas previous studies of the on-site devices have been primarily laboratory based. Moreover, the current study provided the opportunity to examine the performance of the devices when used by law enforcement personnel as opposed to trained laboratory technicians. The overall error rates, as indicated when one of the devices on any given sample resulted in an erroneous finding compared to the other four devices, were generally low -- .8\% for research analysts and $2.5 \%$ for officers. Although the rates were low, the error rates for the officers were higher than those for the research analysts in total and for every device except TesTcup ${ }^{\circledR}$. This finding suggests that additional training and experience is needed if the on-site devices are to be used routinely by law enforcement officers.

\section{RECOMMENDATIONS}

The findings and conclusions discussed above lead the research team to propose the following recommendations:

1. Although previous studies have demonstrated that drug use by erratic, injured, and fatally injured drivers is a problem, these studies (and the current study) all have a serious and common limitation. Principally, as pointed out by Compton and Anderson (1985), the research was not designed to provide an estimate of the extent of drug use by the general driving public. This is a very important consideration in determining whether drug use is 
over represented in erratic, injured and fatally injured drivers. Previously, study populations have been selected from drivers who have either made an observed driving error, been injured in a crash, or been killed in a crash. Clearly, this is a select group that does not necessarily reflect the general driving population. A study is needed that can sample drivers in a more comprehensive fashion to gain a fuller and more accurate understanding of the prevalence of drug use in the general driving population as opposed to drug use in these select populations.

2. The detection of drugs in addition to the standard DOT/DHHS testing battery in the current study indicates that additional drugs must be included in this battery when testing samples collected from DUI drivers. At a minimum, specimens should be tested for the presence of hydromorphone, hydrocodone and additional chemical analogs of the sympathomimetic amines. A study of samples collected from DUI arrestees that included a "comprehensive" urinalysis drug screen would assist also in identifying additional drugs and metabolites that may be present but typically are not detected. Obtaining urinalysis drug screening information along with blood alcohol concentration (BAC) would provide additional data on the percentage of arrestees who typically would not be charged with a drugs and driving offense because their BACs were sufficiently high to warrant the charge of driving under the influence of alcohol.

3. Periodic studies similar to that described above (2) are needed to identify changes in drug use patterns to ensure that drugs such as MDMA do not go undetected in DUI drivers. The current DOT/DHHS testing battery does not include newer drugs of abuse such as MDMA or ketamine (Vitamin K, Special K) and should be expanded to include these drugs.

4. Additional consideration should be given to reducing the MS confirmation cutoff concentration for highway safety use. In this study, decreasing the confirmation concentrations by one-half would have greatly reduced the number of cases that would have resulted in an unconfirmed positive based on MS testing.

5. A standard assessment protocol should be developed to evaluate new on-site devices prior to their use in DUI testing. Selection of the devices in this study was done systematically and 
with great detail to ensure that the selected devices were made by experienced immunoassay manufacturers and that their reliability was documented in the literature. However, there are numerous devices on and entering the market that may or may not have comparable performance.

6. Specific and detailed training materials and procedures need to be developed to assist law enforcement personnel to use the on-site devices. Discrepancies between the error rates of the on-site research analysts and the law enforcement officers indicate that additional training is needed before these devices can be used effectively in a law enforcement setting.

7. Finally, the use of on-site devices, such as those evaluated in this field test appear to provide supplemental information to enhance the capabilities of law enforcement officers responsible for enforcing drug impaired driving laws. Law enforcement agencies may want to consider the use of these devices, while understanding and attending to the issues of training and confirmation procedures raised in this study, as one component in the enforcement of drug impaired driving laws. 


\section{REFERENCES}

Armbruster, D.A., \& Krolak, J.M. (1992). Screening for drugs of abuse with the Roche ONTRAK Assays. Journal of Analytic Toxicology, 16, 172-175.

Baker, D.P., Guintu, D.A., Mendoza, M.E., Shepp, P.F., Murphy, M.S., \& Greene, M. (1991). ABSTRACT evaluation of Abuscreen Ontrak ${ }^{T M}$ Assays: Correlation between clinically trained Personnel and non-clinical personnel in the field. Presented AAFS New Orleans, LA.

Brookoff, D., Cook, C.S., Williams, C., \& Mann, C.S. (1994). Testing reckless drivers for cocaine and marijuana. The New England Journal of Medicine, 331, 518-22.

Buchan, B.J., Walsh, J.M., \& Leaverton, P.E. (Submitted 1997). Evaluation of the accuracy of onsite multi-analyte drug testing devices in the determination of the prevalence of illicit drugs in drivers. Journal of Forensic Sciences.

Campbell, B.A., Goodell, R.F., \& Linfield, J.M. (1989). A survey of truckers in British Columbia, Canada. Port Coquitlam, British Columbia: British Columbia Trucking Association, (July), $1-48$.

Cimbura, G., Lucas, D.M., Bennett, R.C., Warren, R.A., \& Simpson, H.M. (1982). Incidence and toxicological aspects of drugs detected in 484 fatally injured drivers and pedestrians in Ontario. Journal of Forensic Sciences, 27, 855-867.

Compton, R.P., \& Anderson, T.E. (1985). The incidence of driving under the influence of drugs 1985: An update of the state of knowledge. Department of Transportation (National Highway Traffic Safety Administration) Pub. \# DOT HS 806980.

Crouch, D.J., Birky, M.M., Gust, S.W., Rollins, D.E., Walsh, M.J., Moulden, K., \& Beckel, R.W. (1993). The prevalence of drugs and alcohol in fatally injured truck drivers. Journal of Forensic Sciences, 38(6), 1342-53.

Crouch, D.J., Cheever, M.L., Andrenyak, D.M., Kuntz, D., \& Loughmiller, D.J. (1998). A comparison of ONTRAK TESTCUP ${ }^{\mathrm{TM}}$ and Abuscreen ONTRAK ${ }^{\mathrm{TM}}$ urine drug test results with kinetic immunoassay and GC/MS results. Journal of Forensic Sciences, 38, 35-40.

Crouch, D.J., Farrell, L., Karsch, H., \& Klaunig, J.E. (1997). A laboratory evaluation of noninvasive drug screening devices at multiple sites. Final report to the Department of Transportation National Highway Traffic Safety Administration.

Department of Health and Human Services. (1997). Mandatory guidelines for federal workplace programs. Federal Register, 62(189), 51118-51119. 
Department of Health and Human Services. (1993). Mandatory guideline for federal workplace testing programs. Federal Register, 58(14), 6062-72.

Department of Transportation (Federal Highway Administration). (1992). Drug and alcohol testing programs. 49 CFR Part 350. Federal Register, 57(241), 59516-59586.

Ferrara, S.D., Tedeschi, L., Frison, G., Brusini, G., Castagna, F., Bernardelli, B., \& Soregaroli, D. (1994). Drug-of-abuse testing in urine: Statistical approach and experimental comparison of immunochemical and chromatographic techniques. Joumal of Analytic Toxicology, 18, 278-291.

Fitzgerald, R.L., Rexin, D.A., \& Herold, D.A. (1994). Detecting benzodiazepines: Immunoassay compared with negative chemical ionization gas chromatography/mass spectrometry. Clin. Chem., 40(3), 373-380.

Garriott, J.C., DiMaio, V.J.M., Zumwalt, R.E., \& Petty, C.S. (1977). Incidence of drugs and alcohol in fatally injured motor vehicle drivers. Journal of Forensic Sciences, 2, 383-389.

Hwang, S.M., Huang, S.H., Huang, B.C., \& Chen, C.S. (1994). Evaluation of five commercial amphetamines and opiates immunoassay test kits in Taiwan. Journal Food and Drug Analysis, 2(2), 89-96.

Jenkins, A.J., Darwin, W.D, Heustis, M.A., Cone, E.J., \& Mitchell, J.M. (1995). Validity testing of the accuPINCH ${ }^{\mathrm{TM}} \mathrm{THC}$ test. Journal of Analytic Toxicology, 19, 5-12.

Koch, T.R., Raglin, R.L., Kirk, S., \& Bruni, J.F. (1994). Improved screening for benzodiazepines metabolites in urine using the Triage ${ }^{\mathrm{TM}}$ panel for drug of abuse. Journal of Analytic Toxicology, 18, 168-172.

Lindenbaum, G., Carrol, S., Daskal, F., \& Kapusnick, R. (1989). Patterns of alcohol and drug abuse in an urban trauma center: The increasing role of cocaine abuse. Journal of Trauma, 29(12), 1654-1659.

Lund, A.K., Preusser, D.F., Blomberg R.D., \& Williams, A.F. (1988). Drug use by tractor-trailer drivers. Journal of Forensic Sciences, 33, 648-661.

Mason, A. P. and McBay, A. J. (1984). Ethanol, marijuana, and other drug use in 600 drivers killed in single-vehicle crashes in North Carolina. Journal of Forensic Sciences, 29, 987 1026.

Reeves, V.C., Drake, R.W., Gross, S., \& Hollister, L. (1979). Study of the incidence of delta-9tetrahydrocannabinol (THC) in forensic blood samples from a California impaired driving population. Sacramento, CA: California State Department of Justice, 
Robinson, T.A. (1979). The incidence of drugs in impaired driving specimens in Northern Ireland. Journal of Forensic Sciences, 19, 237-243.

Soderstrom, C., Trifillis, A., Shankar, B., Clark, W., \& Crowley, R. (1988). Marijuana and alcohol use among 1023 patients. Archives of Surgery, 123, 733-737.

Terhune, K.W., Ippolito, C.A., Hendricks, D.L., Michalovic, J.G., Bogema, S.C., Santinga, P., Blomberg, R., \& Preusser, D.F. (1992). The incidence and role of drugs in fatally injured drivers. Report Number DOT HS 808065 . Washington, DC: U.S. Department of Transportation, National Highway Traffic Safety Administration.

Terhune, K.W., and Fell, J.C. (1982). The role of alcohol, marijuana, and other drugs in accidents of injured drivers. Report Number DOT HS 806 81. Washington, DC: U.S. Department of Transportation, National Highway Traffic Safety Administration.

Towt, J., Tsai, S.C.J., Hernandez, M.R., Klimov, A.D., Kravec, C.V., Rouse, S.L., Subuhi, H.S., Twarowska, B., \& Salamone, S.J. (1995). ONTRACT TESTCUP: A novel, on-site, multianalyte screen for the detection of abused drugs. Journal of Analytic Toxicology, 18.

Walsh, J.M., Buchan, B.J., \& Leaverton, P.E. (1997). Detection of illicit drug in drivers. Paper accepted for presentation at the International Council on Alcohol, Drug, and Traffic Safety in Annecy, France, September, 1997.

Williams, A.F., Peat, M.A., Crouch, D.J., Wells, J.K., \& Finkle, B.S. (1985). Drugs in fatally injured young male drivers. Public Health Reports, 100, 19-25.

Willette, R. \& Walsh, J.M. (1998). Drugs, driving, and traffic safety. World Health Organization Pub. \#78, Geneva, Switzerland.

Wu, A.H.B., Wong, S.S., Johnson K.G., Callies, J., Shu, D.X., Dunn, W.E., \& Wong, S.H.Y. (1994). Evaluation of the Triage system for emergency drugs-of-abuse testing in urine. Journal of Analytic Toxicology, 17, 241-243. 
APPENDIX A:

\section{RESEARCH AND DATA COLLECTION GUIDELINES}




\section{Research and Data Collection Guidelines \\ for the}

Field Test of On-Site Drug Detection Devices

Funded by the National.Highway Traffic Safety Administration

ISA Associates.

Alexandria, Virginia

September, 1998 


\section{Field Test of On-Site Drug Detection Devices}

ISA Associates, Inc. and the University of Utah's Center for Human Toxicology (CHT) are conducting a field test of on-site drug testing devices for use by law enforcement personnel. The primary purpose of the field test is to determine the accuracy and utility of commercially available on-site drug testing devices when used by trained police personnel. The study is being funded by the National Highway Traffic Safety Administration (NHTSA).

The project has multiple objectives. The first objective is to ensure that the best commercially available on-site screening devices - for the purposes of police detection of drug presence - are being assessed. We will be evaluating the accuracy of the devices against the most accurate laboratory standard available - GC/MS testing. However, perhaps the key distinguishing feature of this project is that it is a field test. NHTSA and the Center for Human Toxicology have already conducted a thorough laboratory test of the leading on-site drug screening devices. The goal of this project is to assess how well these devices perform when placed in the hands of trained law enforcement personnel as they conduct their routine duties. Techniques that perform well in the laboratory may falter when brought into the "real world" of law enforcement. The research will evaluate how law enforcement officers can use these screening devices as supporting evidence in the detection of drugs in the driving population.

The field test will also allow us to assess how the on-site screening devices can provide additional information for the Drug Evaluation and Classification (DEC) program. DEC officers in the participating sites will assist the project staff in the evaluation of the on-site devices. However, this project will not evaluate the performance of the DEC officers. At the sites, trained Drug Recognition Experts will conduct DEC assessments on DUI and DUID suspects and will also conduct some of the on-site drug testing devices. The officers can then provide their views on various aspects of the on-site drug tests including, ease of use, time necessary to conduct the test, ease of interpreting the drug test results, and the perceived utility of the devices for the detection of drugs. The results of the field test should provide information on the extent to which these devices can be used to strengthen and enhance the DEC program. This research began in October, 1997 and will be conducted over two years. 


\section{Specific Objectives}

The specific objectives of the study are as follows:

1) To examine and select the most promising on-site drug screening devices for use by police in detecting the presence of drugs.

2) To evaluate the accuracy of the selected on-site drug screening devices when used in a law enforcement field setting to detect the presence of drugs.

3) To evaluate the feasibility of using on-site drug screening devices in a law enforcement field setting as supporting evidence of drug use.

Sponsors of the study. This project is being funded by the National Highway Traffic Safety Administration, part of the Federal Department of Transportation. The Principal Investigator for the study is Royer Cook, Ph.D., President, ISA Associates (ISA) and the Project Director is Dennis Crouch, Assistant Director, Center for Human Toxicology. Rebekah Hersch, Ph.D., Vice President, ISA, is the Field Test Coordinator and will be directly responsible for training and supervising the Research Analysts. ISA Associates is a behavioral science research firm dedicated to research and development in health promotion, substance abuse prevention, and criminal justice.

As a Research Analyst for the Study you should be able to describe the study in brief, summarize the purpose of the survey, and identify the sponsors of it to anyone who asks. 


\section{Principles of Research Data Collection}

The data collection principles in this section may be familiar to you, but we feel certain aspects should be emphasized. The following review covers the central principles you need to know before you start data collection.

\section{Confidentiality}

Persons working in jobs and professions that deal with the behavior of people have a moral duty toward these people. Social science research is one of these occupations, and researchers must honor the ethics of the profession. Thus, all information obtained from participants is privileged, and the Research Analyst must respect their confidentiality and privacy completely.

The Research Analyst will have confidential information about the participant to which they would not normally have access. Your protection of all information about participants gained during the conduct of research is, therefore, essential. We have promised participants that we will not reveal the results of their tests (unless they provide their consent). Participants' data will be combined with those of others in the data collection and the results will be reported as group percentages and totals in such a way that no participants name could be associated with any results.

\section{IT IS YOUR DUTY TO KEEP THE PROMISE OF CONFIDENTIALITY. NEVER TELL FACTS ABOUT, OR REVEAL INFORMATION ABOUT ANY PARTICIPANT. Information or results collected during the study can be shared only with the research team, whose members are under the same ethical and moral duty to the people interviewed as you are.}

The Privacy Act of 1974 deals with the rights of privacy of research participants. These laws require that data collected for the federal government be kept absolutely confidential, and that the participant must be told the purpose of the data collection, what use will be made of the data, and that participation is voluntary. Violation of the Privacy Act of 1974 can involve substantial criminal penalties. The procedures developed for this data collection are in accordance with the Privacy Act of 1974. By adhering to these procedures, the Research Analyst (RA) will help ensure that the data are collected in compliance with the law. 
Procedures to ensure confidentiality. ISA is firmly committed to the principle that the privacy of individuals who provide data through our data collection methods must be protected. To ensure this privacy, the following procedures will be followed:

- Each participant will receive a consent form that will describe the purposes and uses of the information, the voluntary nature of the data collection, and a guarantee of confidentiality.

- Information collected with our instruments will be used for this study only. Upon completion of the tests, the information will be sent directly to ISA and no other individuals outside the research team will see them. The only exception to this rule is if a defense attomey asks for the results of the tests for his/her client or if a participant is charged with a drugs and driving offense and tests negative on all five of our tests. If the latter occurs, the District Attorney's office will be notified as that information is beneficial to a defense attorney.

- All data shall be kept in a secure location when not being used during routine research activities. Access to the data shall be limited to only those persons who are working on this study.

- The tests will be completely confidential. The data collection will, obviously, not be anonymous. However, the Officers and Research Analysts should stress that no names are recorded on the data collection instruments. Participants will be identified only by code numbers which will be known only to the research team.

- The interviewer will not discuss any participant's results with anyone outside the research team and the officers participating in the study.

\section{Use of the data}

The purpose of the this study is to determine the accuracy and utility of commercially available on-site drug testing devices when used by trained police personnel. The data that will be collected will be used solely to determine the validity, reliability, and utility of these devices for the enforcement of DUI laws. At no time will the results of the tests be used to prosecute the research participants. The results of the data collection will be summarized in reports to NHTSA, published reports, and articles on the study. These reports and articles will be disseminated to interested practitioners, policy makers, and researchers across the U.S., and should be of special interest to law enforcement practitioners. All results will be reported in group fashion, with no individual identities revealed. 


\section{The Role of the Research Analyst}

The Research Analyst is to assist ISA in actual data collection. You will have primary contact with the law enforcement officers and, to some extent, the research participants. The data we collect will only be as good as the researchers who conduct the data collection. Private and public agencies will depend on accuracy of the data collected to make decisions that may affect people in all walks of life. Therefore, the Research Analyst's job is especially important and meaningful.

The Research Analyst must conduct the tests in an objective, unbiased manner and assist the law enforcement officers to also conduct the tests in a uniform and unbiased manner.

\section{General Conduct}

You will be working approximately 8-hour shifts. There will, of course, be the necessity to take a break to eat and to use the rest rooms. Please be sure that you secure the test results and data collection materials before leaving the area for any reason. All food and beverages must be kept away from the test devices, urine samples, and work areas. ISA has obtained the cooperation of the Field Test Sites and they will allow us to use their offices and facilities. However, we are guests of the Police Department. Please keep all work areas neat and orderly and leave the offices in the same condition you found them. In addition, please follow all Officer requests involving security issues. 


\section{The Data Collection Tools}

Five devices have been selection for inclusion in this study. They represent a range of manufacturers and technology - from relatively simple to more complicated. The tests selected for use in this study are:

TesTcup, Roche Diagnostic Systems, Inc, Somerville, NJ

Triage, Biosite Diagnostics, San Diego, CA

AccuSign, Princeton Biomedical Corporation, Princeton, NJ

Rapid Drug Screen, American Bio Medica Corp, Ancramdale, NY

TesTstik, Roche Diagnostics Systems Inc., Somerville, NJ

Information about how these tests were selected is available and can be provided if requested. A brief description of each of the five tests is provided below. Additional information about each test is appended.

TesTcup - 5. TesTcup-5 is an integrated urine collection and testing device. Typically, the urine collection and testing is conducted using the collection cup with no urine or reagent handling. For the purposes of this study, however, it is likely that the urine sample will be collected in a separate specimen collection cup and transferred to the TesTcup. TesTcup allows for the simultaneous detection of amphetamines, cocaine metabolite, morphine (opiates), PCP, and THC metabolite. Results are obtained in approximately 5 minutes without timing. The test results are obtained using the following steps:

1) Add specimen to cup ( $30 \mathrm{ml}$ is recommended)

2) Close lid by gently pushing down on the lid and turning the lid to the "TEST" position

3) Tilt cup toward test strip for a full count of 10 seconds - DO NOT INVERT THE CUP

4) Wait for all "TEST VALID" bands to appear. Timing is not required

5) Remove Results label and place on opposite side of the cup. Read each result

6) Read Detection Zones:

Negative Results: A sample is positive if a color bar appears in any of the Drug Detection Zones adjacent to the drug names.

Positive Results: A sample is negative if no color bar appears in any of the Drug Detection Zones adjacent to the drug names.

7) Close lid by turning to "stop" position for storage and shipment. 
Triage. Triage also simultaneously tests for amphetamines, cocaine metabolite, morphine, PCP, and THC metabolite. Triage requires more handling and manipulation of the urine sample and reagents than the other devices. The procedure for using Triage is as follows:

1) Using a Biosite Pipette provided, attach a clean, disposable tip to the pipette

2) Depress the plunger until it stops

3) Holding the pipette vertically, place the end of the tip into the urine sample to obtain $140 \mathrm{~mL}$

4) Slowly release the plunger, allowing the tip to fill with sample. Withdraw the tip from the sample when the plunger is fully released

5) To dispense the sample (see \#6 below) gently depress the plunger until it stops, discard the tip immediately after use

6) Add the sample to the test by sliding the cap from the reaction cup and dispense the urine sample $(140 \mathrm{~mL})$ into the reaction cup and incubate 10 minutes at room temperature

7) Using the pipette provided, attach a new clean pipette tip, carefully transfer the reaction mix from the reaction cup to the point in the Detection Area indicated by the arrow. Allow the mixture to soak through completely.

8) After the Detection Area is completely dry, add 3 drops of the Wash Solution into the center of the detection area and allow to soak through completely. Read the CONTROL NEGATIVE (CTRL NEG) Zone, the CONTROL POSITIVE (CRTL POS) Zone, and the Drug Detection Zones. Result may be read anytime within 5 minutes of completion

9) If the color bar appears in the CTRL NEG Zone, discard the test and retest the sample using a new device

10) Results are VALID if a color bar appears in the CTRL POS Zone. If no color bar appears in the CTRL POS Zone, discard the device and retest the sample using a new device.

11) Reading the Detection Zones:

Positive Results: A sample is positive if a color bar appears in any of the Drug Detection Zones adjacent to the drug names.

Negative Results: A sample is negative if no color bar appears in any of the Drug Detection Zones adjacent to the drug names. 
AccuSign. AccuSign is a single step procedure that simultaneously tests for the presence of the five drugs listed previously. Precise timing is not required for the AccuSign test, although the test should be read within 10 minutes. Procedures for AccuSign are all follows:

1) Using the plastic pipette, remove a sample of urine from the collection cup

2) Add 3 drops of urine from the pipette to the Sample Well.

3) Read results in 2-5 minutes (within 10 minutes)

4) Interpret the results:

CONTROL LINE: A colored line indicates the test is complete and the system has work properly.

NEGATIVE: A colored line for the specified drug indicates the test is negative and the drug was not detected.

POSITIVE: No colored line for the specified drug indicates the test is positive and the drug was detected.

Rapid Drug Screen. Rapid Drug Test is a single step process that simultaneously tests for the presence of the NIDA-5 drugs. Results can be obtained in 3 minutes and must be read within 10 minutes. Procedures for Rapid Drug Screen are all follows:

1) The test cup should be filled with the urine sample to the level indicated in the blue area of the cup

2) The cup should then be covered with the cap with "SAFETY SEAL" tape

3) Remove the Rapid Drug Screen Test Plate from the foil pouch before use

4) Using the corner of the Rapid Drug Screen, slit the safety seal tape in the lid of the cup

5) Insert BLUE END of the Rapid Drug Screen through the slit in the lid of the cup and allow it to touch the bottom of cup

6) Set the cup aside for three minutes

7) A NEGATIVE RESULT for a particular drug is indicated by TWO LINES in the drug detection box: (Negative results can be read after three minutes)

8) A POSITIVE RESULT for a particular drug is indicated by a SINGLE LINE in the drug detection box: (Positive results will be evident in 8-10 minutes)

9) If no lines appear in the test area, retest with a fresh Rapid Drug Screen

NOTE: The intensity of the line is not important. The appearance of any line, no matter how strong or weak it appears, should be considered a line in the test area. 
TesTstik. The TesTstik assay is a single-analyte test that can detect for the presence of a specific illicit drug. Each TesTstik is specifically designed to detect one illicit drug. Several TesTstiks may be dipped into the specimen container simultaneously as long as there is sufficient sample to reach the "DIP LINE." This can be accomplished by holding the TesTstiks back to back so the Dip Line is visible. Five TesTstik Tests will be conducted (one for each of the five drugs) for each sample. The procedure for each TesTstik is as follows:

1) Each device is individually wrapped. Gently tear the foil pouch to remove the stick

2) Fully retract the protective sample pad cover by sliding it toward the opposite end of the TesTstik until it can go no further

3) Gently immerse the exposed sample pad into the specimen until the urine specimen reaches the DIP LINE. DO NOT IMMERSE THE ENTIRE DEVICE. If there is insufficient sample to reach the Dip Line, gently tip the container until the specimen reaches the Dip Line

\section{KEEP THE TESTSTIK IN THE SPECIMEN FOR A COUNT OF 10}

4) Remove the TesTstik from the specimen. While holding the TesTstik over the specimen cup, push the sample pad cover forward until it stops to cover the sample pad

5) Allow the test to proceed until a distinct blue band forms in the "TEST VALID" window. The TesTstik may be placed on a level surface or held while the band is developing. There is no required timing.

Once the TEST VALID line appears, remove the tab to expose the results window

6) A BLUE BAND in the RESULTS window indicates a NEGATIVE result

7) NO COLOR in the RESULTS window indicates a POSITIVE result (The window appears as a white $(+)$ sign. 


\section{Field Procedures}

\section{The Site Coordinator}

Dr. Rebekah Hersch and Mr. Dennis Crouch will monitor and supervise your work. Dr. Hersch will have weekly contact with you to discuss the data collection and any issues that arise. In addition, she or Mr. Couch (or Dr. Royer Cook) will conduct periodic site visits. Data collection forms should be sent to ISA each week. Samples with a positive screen for any drug on any of the kits will be stored in a refrigerator on-site and shipped in batches via Airborne Express Lab Pack to the Center for Human Toxicology. In addition, if a participant tests is charged with a drugs and driving offense and tests negative on all five of the on-site devices, the specimen will also be labeled, stored, and shipped to the Center for Human Toxicology. ISA will supply all of the materials needed for storing and shipping the specimens. Dr. Hersch will be available anytime by telephone if a problem arises. Dr. Hersch's number at ISA is 703/739-0880.

The following sections provide most of the necessary information, procedures, and forms needed for the successful completion of the study.

\section{Preparation}

Review your manual and the data collection forms and procedures until you are sure you understand all aspects of your job. This includes understanding the purpose of the study and your role in it, going over general principles of data collection, learning the field procedures, and understanding the specifications of the data collection devices and forms.

Before you begin your first data collection session, review the device inserts and practice using the devices and forms until you feel confident. Successful data collection requires an RA who fully understands and can easily and correctly use the materials.

Be sure you know which materials you need before you go to the police department, to ensure that you have everything that you will need. Also, organize your materials and be accustomed to handling them so you don't find yourself fumbling or dropping the materials.

\section{Data Collection.}

ISA has requested that officers in the DUI Central Testing/Processing Section ask each DUI arrestee brought into the Section whether they would be willing to participate in a voluntary study. 
In some cases, arrestees may not be approached to participate (e.g., too inebriated, too belligerent, etc.). Arrestees will be informed that information obtained as part of this study WILL NOT be used against them in a criminal or civil proceeding. If the arrestee declines to participate, a notation should be made so that the RA can obtain an accurate count of the number of arrestees asked to participate and the number who refused to participate. If the arrestee agrees to participate, s/he must sign the informed consent document and be given a copy for her/his records. The Officer will then obtain a urine sample from the participant. Because the test results will not be used as evidence in any legal proceeding, the Officers will not be required to use chain-of-custody procedures. Participants can provide a sample privately at the Officer's discretion.

\section{Testing the Samples}

The Participant's sample will be given to the RA. The RA will be responsible for assigning the appropriate identification number to the sample. (The RA should also record the name and identification number on the Master List. In addition, the RA should indicate on the Master List, the name of the Officer who conducted the test and the name of the device the Officer used.) Prior to data collection, ISA will provide a Test Order Form so the RA will know in what order to conduct the tests. The order of the tests will rotate for each sample to avoid any bias. For each sample, the Testing Officer will be assigned the first kit in the order. (In the case of TesTstik, the Officer will conduct all five TesTstiks on the sample). If possible, those tests will be conducted first. If not, the device will be set aside so that the Officer can complete the testing as soon as feasibly possible. The Testing Officer will conduct the test according to the directions -- from preparation to interpretation of results. Prior to testing, the RA should review the testing procedures and test interpretation with the Officer to ensure that the Officer feel confident using the device. The Officer's test results will then be recorded on the RESULTS LOG. The Testing Officer should interpret the results of the test without assistance from the RA. The RA should observe the Officer conduct the test and note any problems. After the test is completed, the Testing Officer will be asked to complete the Test Rating Form (see below). Officers will need to complete a Test Rating Form for each test device/sample they complete. The RA will proceed to conduct the remaining four tests on the sample in the assigned order (again, if necessary, the Testing Officer can conduct his or her test after the RA conducts the remaining tests). The results of the tests should be recorded on the RESULTS LOG. For a negative result, the " - " sign should be circled, for a 
positive result, the " + " sign should be circled. Be sure to circle the results clearly, so there will be no confusion when the data is summarized. If a DRE evaluation is conducted, please indicate the results of the DRE evaluation as well.

If ALL FIVE DEVICES test NEGATIVE for ALL five drugs, dispose of the urine sample in the bathroom toilet and discard the used devices and collection cups in the biohazard box provided. There is one EXCEPTION to this procedure. If the arrestee is charged with a drugs and driving offense (driving under the influence of something other than alcohol) and we obtained only negative results on all five devices, we need to note that on the master list (a simple * is sufficient) and store the sample for shipment to the CHT. That information (the fact that we failed to obtain any positive test results) will need to be provided to the District Attorney's Office.

Whenever ANY of the five devices tests POSITIVE for ANY of the five drugs, the sample should be sealed and stored for shipment to CHT. The RA will need to record on the sample which drugs require confirmation. For example, for Sample X, two devices resulted in a drug positive for marijuana (THC) and one device also tested positive for cocaine (COC), then a GC/MS confirmation will be needed for both THC and COC. If for Sample Y, five devices tested positive for amphetamines (AMP) and one tested positive for THC, then again there would be two GC/MS confirmations needed (THC and AMP). Finally, if for Sample Z, only one device tested positive for cocaine only, then the sample would be sent to CHT to be confirmed for COC. Samples requiring confirmation will be sent weekly to $\mathrm{CHT}$. Information on specimen collection and shipping is presented below.

\section{Specimen Collection.}

CHT will provide $100 \mathrm{~mL}$ inert plastic collection cups for urine collection. Following collection, use the markers provided containing indelible black ink to label the cup. At a minimum, the label should include:

(1) study identification number, and

(2) date and time of collection.

Urine from the collection cup will be used to dispense aliquots for on-site device testing. After testing, specimens may be stored (refrigerated) in the collection cup. If storage space is a problem, the specimen may be transferred to a shipment bottle (see below). Be sure to label the bottle with the information that was on the specimen cup label. 


\section{Specimen Shipment}

CHT will provide sample shipment kits containing the following materials -

1) $30 \mathrm{~mL}$ screw cap specimen bottles;

2) Specimen labels;

3) Fluid tight, leak proof, self-sealing specimen bags; and

4) Each bag contains an absorbent packet.

You will also be provided with a specimen manifest form; pre-printed shipping labels and 'bill recipient' overnight courier shipment forms. Costs associated with the shipment of urine specimens from the site by Airborne Overnight service will be billed to CHT. Our cost estimate is based on 15 urine specimen/shipment. However, you should send specimens at least every other week to avoid prolonged storage.

\section{Labeling Procedure for Specimen Bottles}

Use indelible black ink to write on labels. At a minimum the label should include:

(1) study number,

(2) date and time of collection, and

(3) drug(s) to be confirmed.

Attach the label securely to the bottle and record information on the inventory and shipment form.

\section{Shipping}

When an appropriate number of specimens have accumulated (approximately 15), ship samples to:

Bobbie Smith or Dennis Crouch

University of Utah

Center for Human Toxicology

20 South 2030 East

Salt Lake City, UT 84112-9457

Phone 801-581-5117 FAX 801-581-5034

Also, please notify Ms. Smith or Mr. Crouch at the Center for Human Toxicology (801) 581-5117 when specimens are shipped. 


\section{Test Rating Form}

As noted above, Officers will be asked to complete a Test Rating Form for each test they conduct. The form consists of a series of Likert-type scales, designed to assess the Officer's ratings of the test on a number of variables including, easy of use, time needed to conduct the test, time needed to interpret the test results, interpretability of the test results, etc. The RA will provide the Test Rating Form to the Officer and ask the Officer to return it to him/her. Officers will ultimately complete multiple rating forms for each device. The Test Rating Form along with the Results Log will be sent to ISA every two weeks via Federal Express. ISA will provide the Fed Ex packaging and labels.

\section{Key Points:}

- Complete confidentiality of the test results. NO ONE OUTSIDE THE RESEARCH TEAM OR THE OFFICERS INVOLVED IN THE STUDY WILL KNOW THE RESULTS OF THE TESTS.

- Participation is voluntary -- no negative repercussions will result if the arrestees choose not to participate, BUT there are no known risks to participation.

- Benefits of the study: To gain knowledge about how these devices work.

\section{Record Keeping}

The RA will be responsible for recording the results of each device for each drug category. Participants will be identified by unique Identification Number only. Samples that require GC/MS confirmation will also be identified by the same unique identification number. In addition to recording the results, the RA will be responsible for maintaining a Master Code List. This list will link names and identification numbers. The list will only be used in the event that a defense attorney requests information from the District Attorney about the results of the testing. The Master List must be secured in a separate location from the Results Log. Finally, the RA will be responsible for maintaining a Response Rate Record; that is, the number of DUI arrestees asked to participate, the number who refused and the number who agreed. The RA will also be responsible for maintaining and sending the Officer Rating Forms to ISA. 


\section{Other Administrative Matters}

Terms of employment. On-Site Research Analysts are hired as independent contractors. As such, no taxes will be deducted from your pay and you are responsible for paying any resultant taxes. ISA will issue a Tax Form 1099 to each RA at the end of the Tax Year. As in most instances of temporary employment, paid vacations and holidays, medical insurance, retirement benefits, and worker's compensation are not included.

Each Research Analyst has signed an Independent Contractor's Agreement. This agreement outlines the rate of pay, schedule, and responsibilities of the RA. This agreement is in force for the duration of the field work. 
RESULTS LOG

\begin{tabular}{|c|c|c|c|c|c|c|c|c|c|c|c|c|}
\hline CODE & TEST & & \multicolumn{2}{|c|}{ THC } & \multicolumn{2}{|c|}{$\mathbf{P C P}$} & \multicolumn{2}{|c|}{$\mathrm{COC}$} & \multicolumn{2}{|c|}{ AMP } & \multicolumn{2}{|c|}{ MOR } \\
\hline & Triage & & + & - & + & - & + & - & + & - & + & - \\
\hline & TesTcup & & + & - & + & - & + & - & + & - & + & - \\
\hline & AccuSign & & + & - & + & - & + & - & + & - & + & - \\
\hline & Rapid Drug Test & & + & - & + & - & + & - & + & - & + & - \\
\hline & TesTstik & & + & - & + & - & + & - & + & - & + & - \\
\hline & DRE Eval & $\mathbf{N} / \mathbf{A}$ & + & - & + & - & + & - & + & - & + & - \\
\hline
\end{tabular}

\begin{tabular}{|c|c|c|c|c|c|c|c|c|c|c|c|c|}
\hline CODE & TEST & & \multicolumn{2}{|c|}{ THC } & \multicolumn{2}{|c|}{ PCP } & \multicolumn{2}{|c|}{$\mathrm{COC}$} & \multicolumn{2}{|c|}{ AMP } & \multicolumn{2}{|c|}{ MOR } \\
\hline & Triage & & + & - & + & - & + & - & + & - & + & - \\
\hline & TesTcup & & + & $=$ & + & $=$ & + & - & + & - & + & - \\
\hline & AccuSign & & + & - & + & - & + & - & + & - & + & - \\
\hline & Rapid Drug Test & & + & - & + & - & + & - & + & - & + & - \\
\hline & TesTstik & & + & - & + & - & + & - & + & - & + & - \\
\hline & DRE Eval & $\mathbf{N} / \mathbf{A}$ & + & - & + & - & + & - & + & $=$ & + & - \\
\hline
\end{tabular}

\begin{tabular}{|c|c|c|c|c|c|c|c|c|c|c|c|c|}
\hline CODE & TEST & & \multicolumn{2}{|c|}{ THC } & \multicolumn{2}{|c|}{ PCP } & \multicolumn{2}{|c|}{$\mathrm{COC}$} & \multicolumn{2}{|c|}{ AMP } & \multicolumn{2}{|c|}{ MOR } \\
\hline & Triage & & + & - & + & - & + & - & + & - & + & - \\
\hline & TesTcup & & + & - & + & - & + & - & + & - & + & - \\
\hline & AccuSign & & + & - & + & - & + & - & + & - & + & - \\
\hline & Rapid Drug Test & & + & - & + & - & + & - & + & - & + & - \\
\hline & TesTstik & & + & - & + & - & + & - & + & - & + & - \\
\hline & DRE Eval & N/A & + & - & + & - & + & - & + & - & + & - \\
\hline
\end{tabular}

\begin{tabular}{|c|c|c|c|c|c|c|c|c|c|c|c|c|}
\hline CODE & TEST & & \multicolumn{2}{|c|}{ THC } & \multicolumn{2}{|c|}{ PCP } & \multicolumn{2}{|c|}{$\mathrm{COC}$} & \multicolumn{2}{|c|}{ AMP } & \multicolumn{2}{|c|}{ MOR } \\
\hline & Triage & & + & - & + & - & + & - & + & - & + & - \\
\hline & TesTcup & & + & - & + & - & + & - & + & - & + & - \\
\hline & AccuSign & & + & - & + & - & + & - & + & - & + & - \\
\hline & Rapid Drug Test & & + & - & + & - & + & - & + & - & + & - \\
\hline & TesTstik & & + & - & + & - & + & - & + & - & + & - \\
\hline & DRE Eval & $\mathbf{N} / \mathbf{A}$ & + & - & + & - & + & - & + & - & + & - \\
\hline
\end{tabular}

\begin{tabular}{|c|c|c|c|c|c|c|c|c|c|c|c|c|}
\hline CODE & TEST & & \multicolumn{2}{|c|}{ THC } & \multicolumn{2}{|c|}{ PCP } & \multicolumn{2}{|c|}{$\mathrm{COC}$} & \multicolumn{2}{|c|}{ AMP } & \multicolumn{2}{|c|}{ MOR } \\
\hline & Triage & & + & - & + & - & + & - & + & - & + & $=$ \\
\hline & TesTcup & & + & - & + & - & + & - & + & - & + & - \\
\hline & AccuSign & & + & - & + & - & + & - & + & - & + & - \\
\hline & Rapid Drug Test & & + & - & + & - & + & - & + & - & + & - \\
\hline & TesTstik & & + & - & + & - & + & - & + & - & + & - \\
\hline & DRE Eval & N/A & + & - & + & - & + & - & + & - & + & - \\
\hline
\end{tabular}


Field Test of On-Site Drug Detection Devices

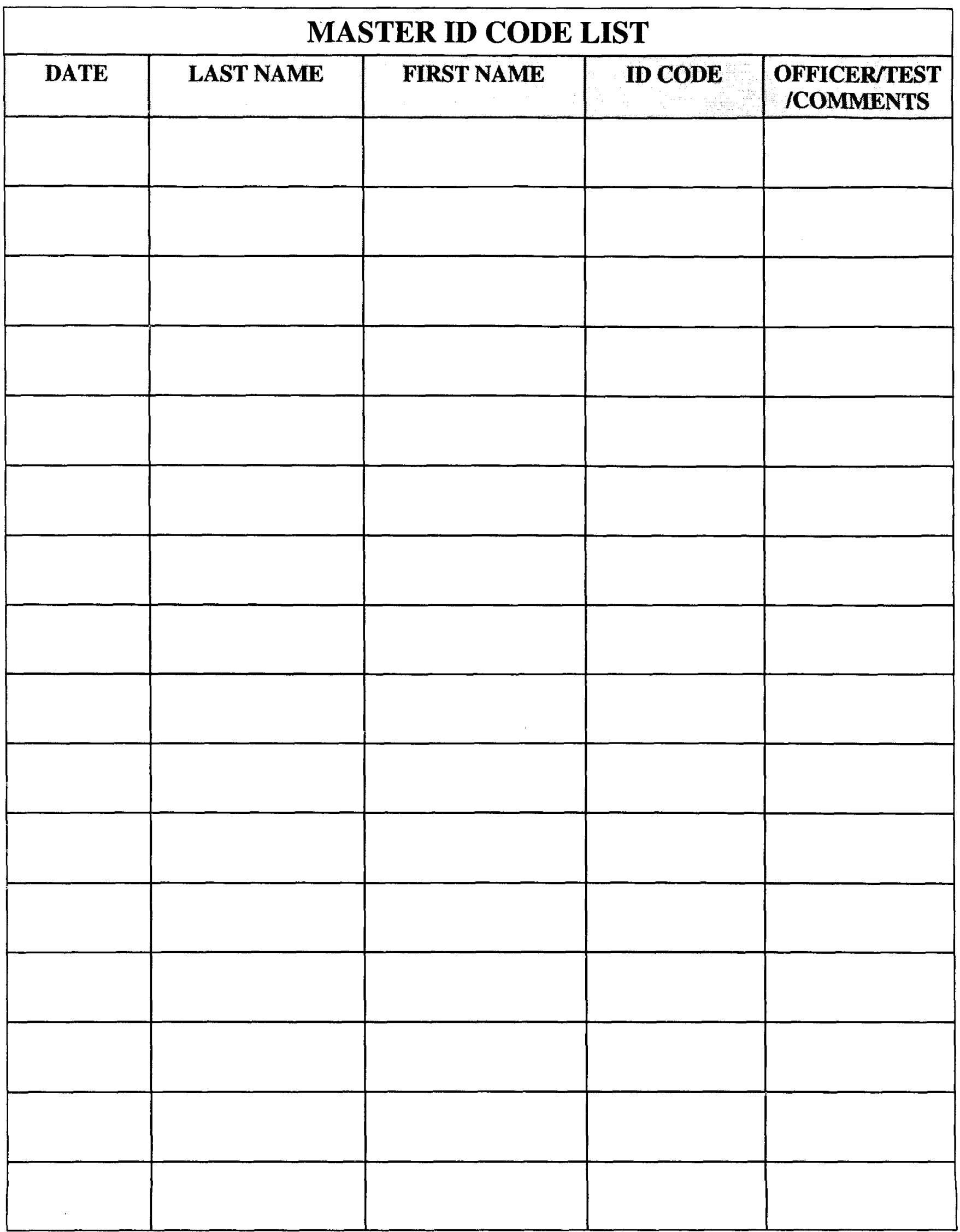




\section{RESPONSE RATES}

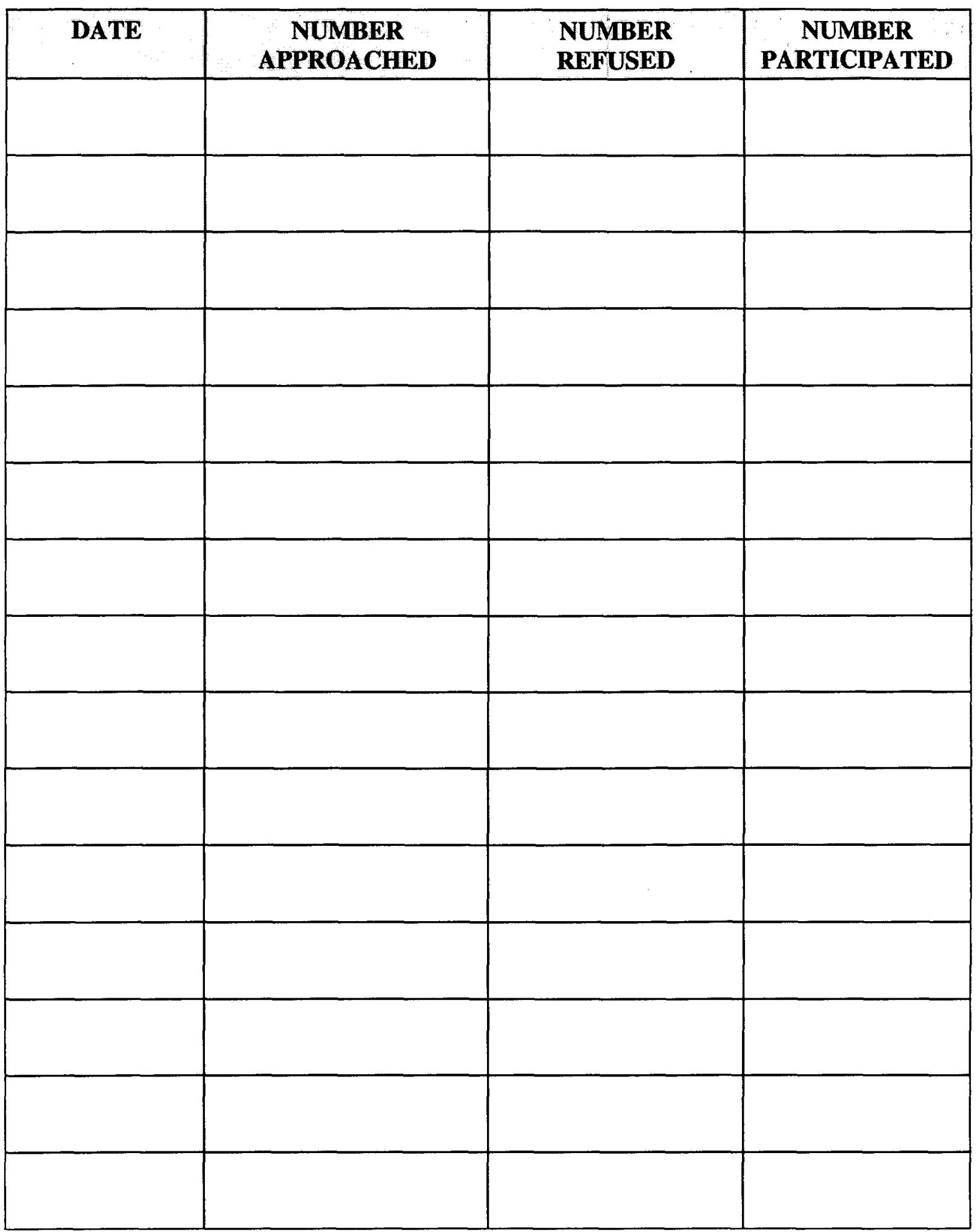


APPENDIX B:

CONFIRMATION TESTING PROCEDURES 
As part of the Field Test of On-Site Drug Detection Devices funded by the National Highway Traffic Safety Administration, the Center for Human Toxicology performed Mass Spectrometry (MS) confirmations all drugs presumptively identified as positive by any of the devices. In addition, $5 \%$ of the samples that tested negative (drug free) were randomly, selected for confirmation testing. For each confirmation test, Gas Chromatography/Mass Spectrometry (GC/MS) confirmation cutoff sensitivities at lower concentrations than those of the federal standards (DOT, 1992; DHHS, 1993) were established. A summary of GC/MS methods and testing limits used in this study follows.

Multi-point calibration curves, containing certified negative urine and at least 4 calibrators were generated by fortifying drug-free urine with the target analytes. Verified negative and positive controls were included in each testing batch. Deuterium labeled drug analogs were used as internal standards to ensure accurate relative retention time information for qualitative identification and for internal standard quantitation. LC/MS and LC/MS/MS testing was used to supplement the GC/MS specifically for the detection of low concentrations of cannabinoids and for the identification of additional sympathomimetic amines and opiates.

All MS data were reviewed and certified prior to reporting. Each confirmation test was performed on a standard volume of $1.0 \mathrm{~mL}$ of urine. Samples testing at concentrations greater than the described calibration curve were reported as positive greater than the highest calibrator concentration (e.g., THC-COOH $>250 \mathrm{ng} / \mathrm{mL}$ ).

THC-COOH confirmations were performed to a testing limit of $4 \mathrm{ng} / \mathrm{mL}$. Each urine was hydrolyzed at basic $\mathrm{pH}$, extracted, derivatized with pentafluoropropionic anhydride/ hexafluorisoprapanol (PFPA/HFIP), and subjected to GC/MS analysis by negative ion chemical ionization with selected ion monitoring. Samples that proved unsuitable for GC/MS analyses were confirmed by LC/MS/MS. These samples were hydrolyzed at a basic $\mathrm{pH}$, extracted and subjected to LC/MS/MS analysis using positive ion electrospray ionization with selected reaction monitoring.

A cocaine confirmation consisted of testing for parent cocaine and benzoylecgonine (BZE) to a limit of $50 \mathrm{ng} / \mathrm{mL}$. Each urine was extracted using SPE (solid phase extraction), the BZE derivatized with $\mathrm{N}$-methyl-N-(tert-butyldimethylsilyl)-trifluoroacetamide (MTBSTFA) and subjected to GC/MS analysis for parent cocaine, BZE. The analyses were performed by positive 
ion chemical ionization with selected ion monitoring. Samples that proved unsuitable for GC/MS analyses were confirmed by LC/MS. These samples were extracted by SPE and subjected to LC/MS analysis for parent cocaine and BZE using positive ion electrospray ionization with selected ion monitoring.

An "amphetamines" confirmation consisted of testing for amphetamine, phentermine, and methamphetamine to a limit of $100 \mathrm{ng} / \mathrm{mL}$. In addition, phenylpropanolamine, ephedrine, pseudoephedrine, or methylenedioxymethamphetamine (MDMA) were qualitatively identified. Initially, urine samples were extracted at basic $\mathrm{pH}$, derivatized with trifluoroacetic anhydride (TFAA), and subjected to GC/MS analysis for the listed drugs by positive ion chemical ionization with selected ion monitoring. However, it quickly became apparent that many samples had high concentrations of phenylpropanolamine, ephedrine, pseudoephedrine, and MDMA that adversely affected the chromatography. Therefore, most samples were extracted at basic $\mathrm{pH}$ and subjected to LC/MS analysis for using positive ion electrospray ionization with selected ion monitoring.

An opiate confirmation was performed to a testing limit of $50 \mathrm{ng} / \mathrm{mL}$ for total morphine and codeine. In addition, hydrocodone and hydromorphone were qualitatively identified. Each urine sample was hydrolyzed enzymatically, extracted at basic $\mathrm{pH}$, derivatized with TFAA, and subjected to positive ion chemical ionization with selected ion monitoring GC/MS analysis. Many samples contained hydromorphone and hydrocodone. Due to the inherently better analysis characteristics for these drugs by LC/MS, these samples were hydrolyzed enzymatically, extracted by SPE, and subjected to LC/MS analysis for the target opiates using positive ion electrospray ionization with selected ion monitoring.

A phencyclidine confirmation consisted of testing for PCP to a limit of $5 \mathrm{ng} / \mathrm{mL}$. Each urine was extracted at basic $\mathrm{pH}$ and subjected to GC/MS analysis for PCP. The analysis used positive ion chemical ionization with selected ion monitoring. 


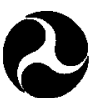

U.S. Department of Transportation

National Higlwway

Trefitis Safely

Administretion

Poupla 8aving Paopls

mumentaditery

DOT HS 809192

October 2000 